\title{
Death-defying Morphologies: Mass Extinction and Disparity in the Order Harpetida
}

James Desmond Beech

jdb0054@mix.wvu.edu

Follow this and additional works at: https://researchrepository.wvu.edu/etd

Part of the Paleobiology Commons, and the Paleontology Commons

\section{Recommended Citation}

Beech, James Desmond, "Death-defying Morphologies: Mass Extinction and Disparity in the Order Harpetida" (2019). Graduate Theses, Dissertations, and Problem Reports. 4064.

https://researchrepository.wvu.edu/etd/4064

This Thesis is protected by copyright and/or related rights. It has been brought to you by the The Research Repository @ WVU with permission from the rights-holder(s). You are free to use this Thesis in any way that is permitted by the copyright and related rights legislation that applies to your use. For other uses you must obtain permission from the rights-holder(s) directly, unless additional rights are indicated by a Creative Commons license in the record and/ or on the work itself. This Thesis has been accepted for inclusion in WVU Graduate Theses, Dissertations, and Problem Reports collection by an authorized administrator of The Research Repository @ WVU. For more information, please contact researchrepository@mail.wvu.edu. 


\section{WestVirginiaUniversity \\ THE RESEARCH REPOSITORY @ WVU}

Graduate Theses, Dissertations, and Problem Reports

2019

Death-defying Morphologies: Mass Extinction and Disparity in the Order Harpetida

James Desmond Beech

Follow this and additional works at: https://researchrepository.wvu.edu/etd

Part of the Paleobiology Commons, and the Paleontology Commons 
THE ORDER HARPETIDA

\author{
James D. Beech \\ Thesis submitted \\ to Eberly College of Arts and Sciences \\ at West Virginia University \\ in partial fulfillment of the requirements for the degree of \\ Master's of Science in \\ Geology
}

\author{
James Lamsdell, Ph.D., Chair \\ Kathleen Benison, Ph.D. \\ Curtis Congreve, Ph.D. \\ Department of Geology \& Geography
}

Morgantown, West Virginia

2019

Keywords: extinction, disparity, end-Ordovician, morphospace, phylogeny, trilobites

Copyright 2019 James Beech 


\begin{abstract}
Death-defying Morphologies: Mass Extinction and Disparity in the Order Harpetida
\end{abstract}

James Beech

The trilobite order Harpetida has long been easily recognized but poorly understood. This study seeks to better understand the phylogenetic relationships within Harpetida, with a view towards using this group to explore the relationship between extinction intensity and disparity. The harpetid response to the Late Ordovician mass extinction is of particular interest. A discrete morphological character matrix was created from the formal descriptions of harpetids in the published trilobite literature, and refined using first-hand observations of harpetid fossils. The final matrix consists of 76 discrete characters, including 69 cephalic characters, three thoracic characters, and four pygidial characters. This matrix is the first attempt of its kind to characterize the morphology of Harpetida as a whole, rather than focusing on individual harpetid genera. Exemplar species from a broad selection of harpetid genera, along with ptychopariid and redlichiid out groups, were included in the matrix. These taxa were coded from published figures and from direct observation of specimens held in the collections of the Yale Peabody Museum of Natural History. From the matrix, a hypothetical tree of harpetid phylogenetic relationships was generated. The topology of this tree indicates support for harpetid monophyly but throws doubt onto the previous hypotheses of the internal relationships of the group. Disparity analysis of Harpetida reveals a decline in morphological diversity following Late Ordovician, with slow or nonexistent recovery. 


\section{CONTENTS}

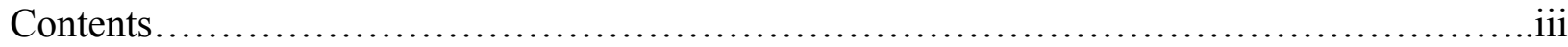

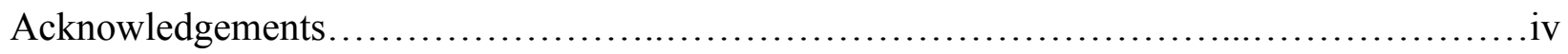

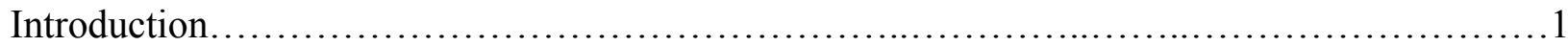

The Nature of Disparity..............................................................

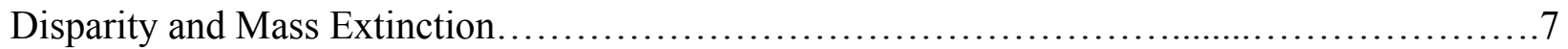

Phylogenetic Approach......................................................... 10

Methods............................................................................

Phylogenetic Methods......................................................11

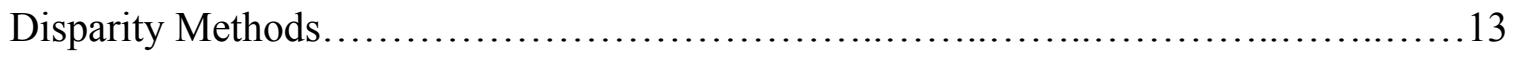

Results.............................................................................

Phylogenetic Analysis.....................................................

Disparity Analysis........................................................ 16

Discussion.................................................................... 19

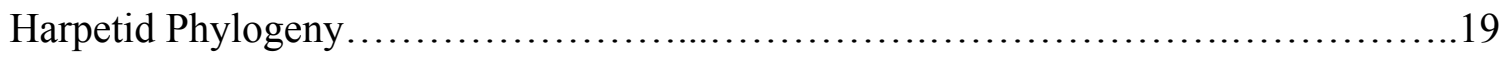

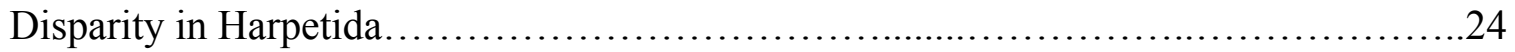

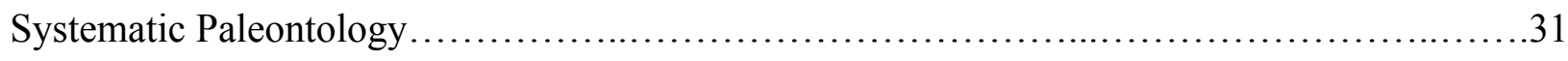

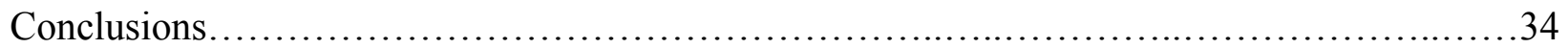

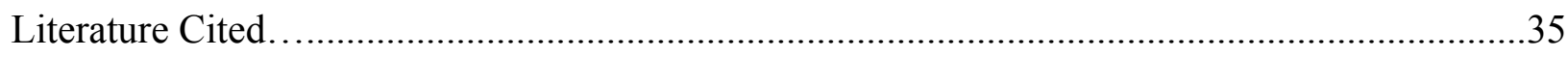

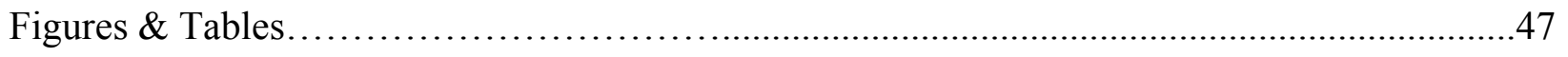

Appendices........................................................................ 59 


\section{ACKNOWLEDGEMENTS}

First and foremost, I would like to thank James Lamsdell for his unfailing support in every aspect of this endeavor. I would also like to thank Kathleen Benison and Curtis Congreve for their invaluable feedback on the scope, specifics, and presentation of this project. I am also indebted to Thomas Hegna for his expert advice on selecting an appropriate out group for Harpetida and to Karla Hubbard and Kirk Pearson for their consultation on the ecological role of the harpetid brim. This work would not have been possible without the support of West Virginia University, and the Yale Peabody Museum of Natural History and their Schuchert and Dunbar grants-in-aid program. Moreover, I would like to thank Susan Butts and Jessica Utrup for all their help in accessing and analyzing harpetid trilobite fossils. 


\section{INTRODUCTION}

The Late Ordovician (end-Hirnantian) mass extinction was the first of the five major extinction events to shape the evolutionary history of the Phanerozoic (Raup \& Sepkoski 1982) and was responsible for eliminating an estimated $85 \%$ of marine species (Sheehan 2001). Of these five mass depletions of biodiversity, the Late Ordovician was the second most severe in terms of percent genera and families extinguished (Sepkoski 1996). The Late Ordovician is also thought to be one of three "true" mass extinctions, driven by an actual increase in extinction rates rather than by low rates of origination (Bambach et al. 2004; Holland \& Patzkowsky 2015). The mass extinction is attributed to a brief period of intense glaciation at the South Pole, and is thought to have occurred in two discrete pulses (Congreve 2013a; Harper et al. 2014). The first of these is attributed to the sudden onset of glaciation during otherwise very warm conditions, and the second to the retreating of the ice sheet and the displacement of anoxic waters onto the continent (Sheehan 1973; Sheehan 2001; Brenchley et al. 2003; Congreve 2008; Finnegan et al. 2011; Sclafani et al. 2019).

Whether the Late Ordovician mass extinction had a meaningful, long term impact on evolutionary history has been called into question (Droser et al. 2000; McGhee et al. 2004; McGhee et al. 2012). In particular, McGhee et al. (2004) stated that the extinction failed to eliminate any key taxa or evolutionary traits and was of minimal ecological impact. However, recent work (Congreve et al. 2019; Scalfani et al. 2019) has challenged this perception, suggesting that many groups that survived the Late Ordovician mass extinction nevertheless experienced significant shifts in their morphologies and the course of their evolution. I hope to 
shed light on this issue by exploring whether Harpetida experienced such a shift following the Late Ordovician mass extinction.

Mass extinction events are agents of wholesale ecological turnover and, ultimately, create constraints on the long-term evolutionary success of clades (Harper et al. 2014). While much work has been done to explore the effects of these events on taxonomic diversity, there have long remained many unanswered questions about their impact upon disparity (e.g. Dommergues et al. 1996; Lupia 1999; Thorne et al. 2011; Bapst et al. 2012; Korn et al. 2013; Ruta et al. 2013; Sclafani et al. 2019). Why do some extinction events remove morphologies at random, while others are highly selective (Raup 1992; Jablonski \& Raup 1995; Jablonski 2001; Korn et al. 2013)? Why is it that some clades emerge from an extinction event lacking the ability to colonize new areas of morphospace (Thorne et al. 2011), while others seem primed for morphological innovation (Bapst et al. 2012)? Resolving these issues is important for understanding the patterns of evolution and extinction in the fossil record and for predicting how modern systems may respond to future mass extinctions (Dirzo et al. 2014).

Previous studies have suggested that trilobites in particular expressed unique patterns of survivorship at the Late Ordovician mass extinction. Chatterton and Speyer (1989) focused primarily on trilobite developmental strategy during the Late Ordovician and demonstrated that a planktonic larval stage greatly increased the vulnerability of species to extinction. Congreve and Lieberman (2011) supported this finding by demonstrating that sphaerexochine trilobites, which are thought to have had benthic larvae, were largely unaffected by the Late Ordovician mass extinction. However, the closely related Deiphoninae seem to have been much more strongly affected by the Late Ordovician mass extinction, despite having a similar life strategy and distribution (Congreve 2013b), suggesting additional complexity. Additionally, the Late 
Ordovician mass extinction eliminated all trilobites with a presumed pelagic adult life strategy (Chatterton and Speyer 1989). Another important factor in survivorship and recovery may have been cold-water adaptation, a possibility explored with homalonotid trilobites by Congreve (2013a). Finnegan et al. (2012) found that the maximum paleolatitude at which a genus had been previously sampled, a macroecological trait linked to thermal tolerance, strongly influenced extinction risk during the Late Ordovician. Finnegan et al. (2016) examined both biogeographic and bathymetric factors and found that the extinction event preferentially affected genera restricted to deeper waters or to relatively narrow paleolatitudinal ranges. All of this seems indicative of a strong ecological component to the mass extinction events. At the family scale, Adrain et al. (1998) found that extinction patterns in Late Ordovician trilobites were related to clade size; trilobite families that survive the mass extinction showed higher genus diversity than families that do not.

To investigate this further, I chose to explore changes in diversity and disparity through time within the trilobite order Harpetida Whittington, 1959 to better understand the relationship between extinction intensity and disparity. Taxonomic diversity measures the number of taxa within a clade; in contrast, disparity, or morphological diversity, strives to measure the range of forms (Foote 1991; Foote 1992; Foote 1993; Foote 1994; Wills et al. 1994; Foote 1995; Foote 1997; Roy \& Foote 1997). Disparity allows us to bridge the gap between an organism's place in the tree of life and its role within an ecosystem by providing a framework for understanding both the evolutionary and functional components of morphology (Foote 1997).

My study focused on the phylogeny and morphology of harpetid trilobites. Harpetida was an order of trilobites that originated 500 million years ago during the Late Cambrian (Hughes 2007) and went extinct during the Late Devonian at the base of the Upper Kellwasser Event 
(McNamara et al. 2009). At present, paleontologists recognize three families of harpetid trilobites and approximately 30 genera (Ebach \& McNamara 2002). Harpetids are identified by the horseshoe-shaped "harpetid brim"; long, flat genal prolongations; reduced eyes, often with strong ridges; a small pygidium; and a forward narrowing glabella (Fortey and Owens 1997). Because harpetid trilobites are morphologically distinctive (Fig. 1), possessing many discrete and clearly identifiable characters (Fig. 2), they are an ideal group for phylogenetic study. In addition, harpetids were one of a handful of trilobite orders to survive the Late Ordovician mass extinction (Hughes 2007). They, thus, afford a unique opportunity to study changes to disparity following one of the first major mass extinctions in Earth's history.

The order Harpetida was named by Whittington (1959) and raised to ordinal status by Ebach and McNamara (2002). The group was previously placed within Ptychopariida, but harpetids are distinguished from true ptychopariids by their marginal facial sutures and lack of a rostral plate (Ebach \& McNamara 2002). Ebach and McNamara (2002) recognizes three harpetid families: Harpetidae, Harpididae, and Entomaspididae. The monophyly of the group is widely accepted, though Adrain (2011) was more conservative. Adrain (2011) preferred to recognize no subclasses, and did not positively identify a unified Harpetida. Instead Adrain (2011) placed the family Harpetidae (including those species previously assigned to Entomaspididae) within the order Harpida, while retaining the family Harpididae as incertae sedis.

Adrain et al. (2004), drawing on the conclusions of Fortey and Owens (1999), described members of the family Harpetidae as belonging to a functional group of small, filter-feeding trilobites, characterized by a vaulted cephalic chamber flanked by genal prolongations, a thorax suspended above the sediment surface, weak axial musculature, an "elevated" hypostome, and (usually) reduced eyes. While highly generalized, this description offers a basis for 
understanding the harpetid morphotype. Recent work in physical modeling (Pearson 2017) has suggested that other members of this functional group are unlikely to have been genuine filter feeders, casting uncertainty onto harpetids' true ecological role. Much of the debate hinges upon the function of the harpetid brim, which has been variously suggested to act as a plough, a sieve, a hydrostatic device, a sensory or respiratory organ, or a method for strengthening and lightening the exoskeleton (Ebach \& McNamara 2002).

\section{THE NATURE OF DISPARITY}

Measures of disparity are, at their most fundamental, attempts to quantitatively describe morphological diversity. Gould (1991) emphasized the importance of this endeavor, stressing that it was the only way to confidently answer fundamental questions about the history of life, such as whether variability reached an early maximum or has continued to build over time. While Gould's vision of a universal, quantified morphospace may never come to fruition, more focused studies have been able to use the concept of morphospace to ask rigorous questions of morphological data. Foote (1997) considered a wide variety of approaches used to study disparity (including morphospace patterning) and concluded that the evolution of morphological disparity is typically non-uniform, often radiating early in clade history while taxonomic diversity remains comparatively low. Hughes et al. (2013) found that clades tend to reach their highest morphological disparity early in their evolutionary history, although this pattern can be truncated by mass extinction events.

McClain (2005) found that in deep-sea gastropods morphospace occupation varies with water depth (although overall disparity remains comparatively stable). An earlier study by 
Dommerrgues et al. (1996), working with Jurassic ammonoids, found tentative evidence to suggest that fluctuations in disparity could be tied to cycles of marine transgression. Hopkins (2014), in a study specifically looking at the fossil record of trilobites, found that habitat affinities contributed significantly to the structure of cranidial morphospace. Together these findings reinforce the idea that environmental factors, as well as phylogenetic ones, contribute to patterns of disparity (Lamsdell et al. 2017; Congreve et al. 2018).

Whatever the driving forces, it has long been recognized that taxonomic diversity and disparity are frequently decoupled (Foote 1993; Lupia 1999; Thorne et al. 2011; Hopkins 2013; Ruta et al. 2013). Hopkins (2013) studied this phenomenon in Cambrian trilobites and concluded that signals of high disparity with low taxonomic diversity are more likely the results of random or mean-targeted extinction, rather than increased rates of morphological diversification. This finding is of particular relevance to this study, given its focus on the harpetid response to increased extinction pressure.

As Hetherington et al. (2015) described, there are two basic ways to quantify disparity. The first is to rely upon the field of morphometrics, which can be further broken down into those techniques that use continuous measurements (traditional morphometrics) and those that use landmarks (geometric morphometrics). However, reliable morphometric data can be problematic to collect when working with taxa with highly variable or divergent morphologies. The alternative approach is to use cladistics characters. Character-based disparity analyses overcome some of the challenges associated with divergent morphology and appear to yield findings comparable to more conventional, morphometric approaches (Villier and Eble 2004; Hetherington et al. 2015). Findings from traditional morphometrics may diverge from other methods of quantifying disparity when very different aspects of morphology are being measured 
(e.g. the overall shape of an echinoid, rather than its tuberculation, plate architecture, etc.)

(Villier and Eble 2004). However, multiple comparative studies have used discrete characters successfully to study shifts in disparity over time and across multiple mass extinctions (Foote 1994, 1999; Wills 1998; Logren et al. 2003; Wesley-Hunt 2005; Young et al. 2010; Thorne et al. 2011; Bapst et al. 2012; Hughes et al. 2013; Ruta et al. 2013; Lamsdell \& Selden 2017).

Brusatte et al. (2011) presented a method for phylogenetically correcting for missing data in studies of morphological disparity. The method infers "ghost lineages" at every node of the phylogenetic tree, reconstructs their character states, and includes them in the disparity analysis as if they were sampled taxa. Halliday \& Goswami (2015) expanded on this approach by introducing the "extended punctuational" method, which gives reconstructed ancestors a temporal range, rather than having them appear only in a single time bin. This technique better enables direct comparisons between disparity measures and taxonomic diversity measures, which are often phylogenetically corrected, and is especially useful for groups with periods of low sampled diversity, such as harpetids.

\section{DISPARITY AND MASS EXTINCTION}

Mass extinctions can impact disparity in various ways. Korn et al. (2013), studying the Devonian and Permian extinction events, suggested that disparity could be reduced during periods of widespread extinction in accordance with one of three general modes. The first mode is (1) essentially random, where available body plans are removed in a nonselective fashion. In this mode, overall morphospace occupation is not affected. The second characteristic mode is (2) marginal, where the edges of morphospace are selectively and symmetrical trimmed. In this 
mode, overall variation is reduced. Finally, the mode of extinction may be (3) lateral, with asymmetric selection eliminating a particular region of previously occupied morphospace. In this mode, the centroid of occupied morphospace shifts position. Additionally, Lamsdell and Selden (2017) examined the disparity of eurypterids and suggested that even when mass extinctions remove morphologies with a high degree of apparent randomness, recovery is often limited to those taxa that share a limited range of body plans. This finding is consistent with the work of Thorne et al. (2011) and Sclafani et al. (2019).

The disparity of monophyletic groups tends to decrease over time, particularly during the interval immediately before or after a mass extinction (Zelditch et al. 2003). Valentine (1995) suggested that this may be due to a decrease in available ecological habitats, while Gould (1991) suggested it may result from an increase in developmental constraints. Crônier expanded on this idea of developmental constraint in her work on phacopid trilobites (Crônier \& Courville 2003; Crônier et al. 2005, 2011; Crônier \& Fortey 2006; Crônier 2007, 2010, 2013). Her findings demonstrated that changes in the timing of development (i.e. heterochrony) were an important source of disparity in trilobites. In times of ecological stress, such as ocean deepening, trilobites tended to revert to more juvenile (pedomorphic), less specialized forms (Crônier 2013). This tendency reduced overall disparity by pushing groups towards a generalized morphology.

Mass extinction events can also have secondary or indirect effects on disparity and diversity. Bapst et al. (2012) found that, following the Late Ordovician mass extinction, graptoloid disparity and taxonomic diversity increased rapidly after an initial period of sharp restriction. This signal was interpreted as strong evidence for adaptive radiation, an evolutionary pattern where a group of organisms diversifies into forms filling different ecological niches, in this case those left vacant following the mass extinction (Bapst et al. 2012). Sunberg (1996) 
observed a similar pattern on a smaller scale during Cambrian biomere events. Following the extinction events associated with these biomeres, trilobite diversity increased in a pattern consistent with adaptive radiation.

Ruta et al. (2013) looked at adaptive radiation in amonodont therapsids following the end-Permian mass extinction. They found that diversity and disparity became decoupled during a period of radiation, with diversity levels bouncing back much more readily than disparity. Amonodont disparity remained low for the rest of their history, and Ruta et al. (2013) concluded that group had emerged from the end-Permian lacking the capacity to fully adapt, radiate, and morphologically diversify. Thorne et al. (2011) observed a similar pattern in ichthyosaurs across the Triassic-Jurassic boundary, where though diversity recovered somewhat disparity remained low until the group's extinction. This pattern is analogous to a "Dead Clade Walking" or DCW (Jablonski 2002) in that it represents a failure to recover following a mass extinction.

Lupia (1999) observed a different kind of decoupled disparity and diversity in the response of angiosperm pollen morphology to the end-Cretaceous mass extinction. The extinction event had little effect on disparity, despite a decrease in taxonomic diversity. In addition, disparity increased in a series of large jumps early in the history of the clade and in smaller jumps later on, a pattern analogous to that seen in the morphological evolution of many marine invertebrates (Lupia 1999; Hughes et al. 2013).

These studies show that responses in disparity to mass extinction events vary widely. To understand this variation, further examples must be added to this growing body of knowledge. By studying harpetids in particular, I hope to address specific gaps in scientific understanding. No previous study has explicitly explored the disparity of Harpetida and many fundamental questions about the order's morphology and phylogeny remain unanswered (Ebach \& 
McNamara 2002). Moreover, the question of selectivity in the Late Ordovician mass extinction remains open (Adrain et al. 1998; McGhee et al. 2004; Finnegan et al. 2012, 2016; Sclafani et al. 2019), especially with regards to trilobites (Chatterton and Speyer 1989; Congreve and Lieberman 2011; Congreve 2013a,b). By using harpetid disparity to explore selectivity during the Late Ordovician mass extinction, this work has the potential to shed light on both of these issues.

\section{PHYLOGENETIC APPROACH}

When using discrete morphological characters to estimate phylogeny, maximum parsimony methods (Fitch 1971; Swofford and Olsen 1990) long remained the only option. However, Lewis (2001) introduced the idea of using Markov models to apply likelihood and Bayesian methods to these sorts of phylogenetic questions. Wright and Hillis (2014) tested this concept rigorously in the context of paleontological studies, using simulated discrete morphological character data. The authors compared the performance of Bayesian inference under a Markov model and parsimony analysis, and found that the Markovian method exhibited lower error rates especially when rates of character evolution were variable or there were large amounts of missing data (Wright \& Hillis 2014). I chose to include both parsimony analysis and Bayesian inference in my examination of Harpetida, for purposes of comparison.

Congreve and Lamsdell (2016) explored another aspect of phylogenetic inference, namely the relative merits of equal and implied character weighting for parsimony analysis in paleontological studies. While implied weighting generally retrieves fewer polytomies, this method also propagates errors and has proved inconsistent in its ability to recreate a known 
phylogenetic tree. Therefore, the authors favored the more conservative method of equal weighting, which—-though it generates more polytomies—is less likely to yield misleading phylogenetic topologies. This is the approach I chose to employ.

\section{METHODS}

Phylogenetic Methods

I summarized harpetid morphology in the form of a comprehensive discrete character matrix (Appendix 2), drawing upon the published trilobite literature. I drew many characters in this matrix from the Treatise on Invertebrate Paleontology (Fortey and Owens 1997) and from Ebach and McNamara (2002), which was a review of harpetid systematics that presented a number of discrete morphological characters - between 3 and 26 for each genus, exclusively concerning the cephalon and related structures - that were incorporated into several genus-level character matrices. This study elevated this work to the ordinal level by synthesizing the relevant characters from these genus-level matrices together with characters drawn from the Treatise and direct observations of specimens housed at the Yale Peabody Museum of Natural History.

Specimens were generally small, between one and three centimeters in length. Some details I could observe with the naked eye, but observation of fine scale structures necessitated the use of an optical light microscope. In general, characters could be assigned a particular state by direct observation alone. Some characters were based on the size of a particular structure compared with the size of a second structure (e.g. genal prolongation length compared to cranidium length). For these characters, I measured structures against a scale bar to a resolution of $.5 \mathrm{~mm}$, using the median of three measurements to account for possible errors. Throughout 
this stage of the process, my objectives were to ensure that my matrix would reflect the real, observable variations in harpetid morphology and to understand how these variations could be obscured by preservation and imaging techniques.

I coded 76 discrete morphological characters (Appendix 1), including 69 cephalic characters, three thoracic characters, and four pygidial characters. I included data coded from 47 species, using 35 physical museum specimens, 14 digital museum specimens, and $\sim 160$ published figures. The coded taxa included 21 of the 29 recognized harpetid genera, and included multiple representatives of each of the three previously recognized harpetid families: Entomaspididae, Harpididae, and Harpetidae. The remaining 8 genera-Chencunia (Qui 1984), Kathrynia (Westrop 1986), Palaeoharpes (Lu and Qian 1977), Dictyocephalites (Bergeron 1895), Kitatella (Petrunia 1960), Metaharpides (Pillet \& Courtessole 1981), Paraharpides (Pillet \& Courtessole 1981), and Pscemiaspis (Abdullaev 1970)—were excluded due to the difficulty of procuring adequate fossil material or figures from which to code character states (Table 1). Six ptychopariid trilobites were included as out group taxa, with the analysis rooted on the redlichiid Eoredlichia intermedia (Lu 1940). Codings were based either on firsthand observation of museum specimens or on photographic figures from the published trilobite literature.

To test harpetid monophyly, I chose to include several ptychopariid trilobites in my analysis. Lamsdell \& Selden (2014) included both ptychopariids and harpetids in a data matrix designed to robustly test the monophyly of proetide trilobites. The work suggested several ptychopariid genera as viable candidates for inclusion in my new matrix, including Modocia, Coosella, Crepicephalus, and Tricrepicephalus. These four taxa represent a broad sampling of Ptychopariida, capturing much of the disparity of the group. In addition, I chose to include representatives of the ptychopariid genera Cedaria and Ptychoparia. The similarity between 
these trilobites and the members of Harpetida has been noted by Rasetti (1948) in his work on the more basal members of the order (i.e. the entomaspidids). The notion of including a trinucleid trilobite (order Asaphida) was considered and eventually discarded on the basis of the high degree of morphological convergence currently assumed between trinucleid and harpetid trilobites (Adrain et al. 2004). To provide structure, the out group was rooted on Eoredlichia intermedia, from the order Redlichiida, thought to be the group that originally gave rise to Ptychopariida during the Early to Middle Cambrian (Hughes 2007).

I performed parsimony analysis in TNT (Goloboff et al. 2008), with Bayesian inference analyses performed using MrBayes 3.2.6 (Huelsenbeck \& Ronquist 2001) with four independent runs of 100,000,000 generations and four chains each under the maximum likelihood model for discrete morphological character data $(\mathrm{Mkv}+\Gamma$ : Lewis 2001), with gamma-distributed rate variation among sites. All characters were treated as unordered and equally weighted (Congreve \& Lamsdell 2016). Trees were sampled with a frequency of every 100 generations, resulting in $1,000,000$ trees per run. The first 25,000,000 generations $(250,000$ sampled trees $)$ of each run were discarded as burn-in, and the 50\% majority rule consensus tree calculated from the remaining 750,000 sampled trees across all four runs. Posterior probabilities were calculated from the frequency at which a clade occurred among the sampled trees included in the consensus tree.

\section{Disparity Methods}

The disparity analysis relied on scripts written in R, adapted from the work of Hughes et al. (2013). Information from the character matrix was converted to generalized pairwise Euclidean distances and combined with the known age ranges of harpetid taxa to track changes 
in disparity over geologic time. Disparity was quantified based on the sums of ranges (measuring amount of morphospace occupied) and of variances (measuring dispersion of taxa around group centroids) (Ruta et al. 2013). The method is non-parametric and founded on an assumption of non-normally distributed morphospace. I binned taxa from the matrix by geologic age and produced morphospace plots, each representing the suite of available morphologies at a different point in the history of Harpetida. Multivariate statistical tests (PERMANOVA - permutational multivariate analysis of variance using the Euclidean distance measure) were performed to verify the statistical significance of overlap and separation of morphospace across all axes between time bins at the period level (Anderson 2017). Significance was estimated by permutation across groups with 9999 replicates. Statistical analysis was performed with Bonferroni correction to control the familywise error rate (Dunn 1961; Armstrong 2014). Particular attention was devoted to changes across the Late Ordovician mass extinction boundary. Morphospace partitions based on established environmental affinities and phylogenetic families were created from the published literature and from the included phylogenetic analyses.

For the final disparity analysis, I included reconstructed ancestors in addition to the sampled taxa to phylogenetically correct for intervals of low sampling. I generated these according the methods described by Brusatte et al. (2011) and Halliday and Goswami (2015). I mapped reconstructed characters onto the nodes of the parsimony consensus tree using Mesquite (Maddison \& Maddison 2018) and coded each node as if it were a sampled taxon. 36 reconstructed harpetids were generated in all. These reconstructed taxa were assigned age ranges using the "extended punctuational" method (Halliday \& Goswami 2015).

RESULTS 
Phylogenetic Analysis

The parsimony analysis yielded 18 most parsimonious trees with an ensemble Consistency Index of 0.456, an ensemble Retention Index of 0.815, a Rescaled Consistency Index of 0.572 , and a tree length of 189. A strict consensus of these trees is shown in Figure 3. Bayesian inference analysis retrieved a broadly similar topology, also shown in Figure 3. The parsimony strict consensus tree showed a monophyletic Harpetida preceded by a paraphyletic grade of ptychopariid trilobites. In the Bayesian analysis Ptychoparia striata appeared as the sister to group to Harpetida, though the parsimony tree failed to achieve this level of resolution (Fig. 3).

Of the three previously recognized harpetid families, two were retrieved as monophyletic clades in both Bayesian and parsimony analyses: the Harpetidae and the Harpididae. By contrast, Entomaspididae consistently appeared as a polyphyletic grade of basal harpetids, with Harpididae resolving within Entomaspididae. The entomaspidid Baikadimapsis jikdongensis appeared as the sister to all other harpetids in both Bayesian and parsimony analyses.

Three taxa previously designated as members of the family HarpetidaeConococheaguea ovata, Bowmania lassieae, and Heterocaryon vargum - also fell within the entomaspidid grade, though this is perhaps unsurprising given how little these taxa resembled their fellow harpetidids. For example, rather than the wide brim typical of Harpetidae, Bowmania sported a fringe of radiating spines (Ludvigsen 1982; Adrain \& Westrop 2004) that likely served a similar ecological function. Conococheaguea and Heterocaryon had no brim-equivalent structure, merely a narrow trough, and-like Bowmania — these genera also displayed a different arrangement of cephalic sutures than most harpetidids. In both Bayesian and parsimony analyses, 
these three taxa formed a clade resolving within the entomaspidid grade, which may indicate support for a natural Heterocaryonidae. This family was proposed by Hupé (1953) but is no longer favored, due to the observed similarity between the genera Heterocaryon and Bowmania and the genus Entomaspis in both cephalic and pygidial structure (Ludvigsen 1982).

The remaining harpetidids formed a large, monophyletic clade. This group included representatives of many recognized harpetid genera. Of these, Eoharpes, Dubhglasina, Brachyhipposiderus, Bohemoharpes, Kielania, Globoharpes, Eskoharpes, and Dolichoharpes appeared as monophyletic in both Bayesian and parsimony analyses. In the parsimony analysis Hibbertia appeared as a paraphyletic grade, while Scotoharpes was found to be polyphyletic. Bayesian analysis retrieved a monophyletic Hibbertia but a paraphyletic Scotoharpes. Both analyses found Lioharpes to be polyphyletic and Harpes to be either polyphyletic or paraphyletic. Collectively this group corresponded well with the established harpetid family Harpetidae and is defined by a wide bilamellar brim, marginal sutures, and small, tuberculate eyes. The entomaspidid trilobite Entomaspis radiatus was retrieved as the sister group to Harpetidae in both analyses.

Disparity Analysis

Disparity analysis yielded differing results for the sampled taxa alone and for the phylogenetically corrected sample, which included reconstructed ancestors. Analysis of the sampled taxa alone showed that while the sum of ranges varied little over the group's history, the sum of variance changed significantly with time. Analyses were made at the period, epoch, and stage levels_ - all revealing broadly similar patterns of variation—but long-term trends may be seen most clearly in the period level graph (Fig. 4). The sum of variance increased modestly 
from the group's origin in the Cambrian through the Ordovician before dropping significantly as the group entered the Silurian. Importantly this decrease in the sum of variance was temporary. By the Devonian, the sum of variance of harpetids had again risen to equal or exceed preSilurian levels. The sum of ranges followed a similar pattern of rise and fall, though these changes were less pronounced. Error bars suggested that both the Ordovician-Silurian drop in the sum of variance and the Silurian-Devonian recovery were statistically significant, as were all shifts in the sum of ranges (Fig. 4). The number of harpetid genera decreased slightly from the Cambrian to Ordovician, decreased more severely as the group enters the Silurian, and recovered somewhat during the Devonian, though never again reaching pre-Silurian levels of genera diversity (Fig. 4).

PERMANOVA (Anderson 2017) testing of generalized pairwise Euclidean distances solely for the sampled taxa showed multiple instances of significant change in morphospace occupation over the history of Harpetida; all four geologic periods showed statistically significant levels of separation (Table 2). The visible morphospace plots produced from the first two principle components serve to illustrate these temporal shifts (Fig. 5). Early harpetids occupied the left-hand portion of the morphospace plot, with the family Harpididae gathering in the upper left quadrant, while the family Heterocaryonidae fell in the lower left. With the diversification of the family Harpetidae in the Ordovician, the order was able to move into new areas of morphospace, coming to occupy the central and upper right portions of the plot as well (Fig. 5). During the Silurian, harpetid morphospace contracted sharply, becoming limited to a small area of the upper central part of the diagram (Fig. 5). Disparity began to recover as the group entered the Devonian and harpetid morphospace expanded once more. The upper right of the plot was recolonized and in a burst of Late Devonian innovation by Eskoharpes, and the 
closely related Globoharpes, the lower right became heavily occupied as well (Fig. 5). However, though overall morphospace occupation recovered as described, harpetids never regained the left-hand portion of the morphospace plot following the Silurian (Fig. 5).

With the addition of reconstructed ancestors, disparity analysis revealed far less variation in disparity. Analyses at the stage and epoch level failed to show statistically significant changes in the sum of variances over time (Fig. 6), but analysis at the period level suggested that harpetid disparity reached its maximum in the Ordovician and then declined steadily until the group's extinction in the Late Devonian (Fig. 7). At all levels of analysis, the sum of ranges likewise showed a slow overall decline following a modest peak in the Ordovician (Fig. 6; Fig. 7).

Phylogenetically corrected harpetid morphospace remained statistically significantly different for all four time periods (Table 3). However, the specific shifts within visible morphospace were materially altered by the addition of reconstructed ancestors (Fig. 8). Early harpetids occupied the right-hand portion of the plot. Morphospace occupation shifted first upwards and then to the left as the group diversified, and morphospace occupation remained concentrated in the left-hand portion of the plot from the Middle Ordovician onward, with the lower left becoming densely occupied during the Late Devonian. Overall morphospace occupation decreased only slightly as the group entered the Silurian.

Studying harpetid morphospace as a whole, it was possible to discern strong phylogenetic zoning. PERMANOVA testing of family level partitions showed highly significant statistical differences in the morphospace occupied by each putative harpetid family, with the lowest levels of significance seen between Entomaspididae and Harpididae (Table 4). In the plot of the first two principal components, the most populous family, Harpetidae, occupied the central and right- 
hand portions of harpetid morphospace, while Harpididae and Heterocaryonidae occupied the upper and lower left respectively, as described (Fig. 9).

In contrast, little to no ecological differentiation of harpetid morphospace could be discerned in a visible morphospace plot. Ellipses were used to indicate the areas of morphospace occupied by harpetids whose fossils have been mutually associated with a particular paleoenvironment (Fig. 10). All of these elliptical partitions overlapped broadly, with little observable signal. However, PERMANOVA testing showed that morphospace occupation did vary significantly between most of these ecological groups (Table 5). This indicated that there was indeed ecological structure to harpetid morphospace, but that it existed outside of the two most significant principal component axes.

\section{DISCUSSION}

Harpetid Phylogeny

Harpetid Monophyly — One of the most basic and significant findings of this study is robust support for the monophyly of the order Harpetida. It is well established that the group originates from ptychopariid stock, diverging from Ptychopariida some 500 million years ago during the Late Cambrian (Hughes 2007). As such, it was necessary to select several ptychopariids for inclusion in the final data matrix, as it could not be known which ptychopariid taxa would prove most closely related to Harpetida, while rooting the phylogeny on a redlichiid trilobite. In both Bayesian and parsimony analysis, the resulting tree shows clearly that Harpetida is a natural group. 
Entomaspidid Polyphyly — In the retrieved phylogenies the base of Harpetida comprises a paraphyletic lineage composed primarily of members of the polyphyletic harpetid family Entomaspididae. Harpididae is nested within this Entomaspididae paraphyletic grade. The harpidid clade includes all three of the harpidid taxa present in the data matrix. The inclusion of additional representatives from the family Harpididae is rendered difficult by the limited availability and completeness of fossil harpidid material; many harpidid specimens are badly fragmented, such as Chencunia, a harpidid genus currently known only from a few partial pygidia from the Upper Cambrian of China (Qui 1984). Despite these difficulties, the existence of a well-supported monophyletic harpidid clade in these analyses indicates that the family Harpididae is a natural group. This group is defined by several morphological characters, such as a genal ridge running posterolaterally from the eye; concave genae; radiating, anastomosing genal cacae; an expanded L3; and the lack of genal spines. In addition, some (though not all) harpidids are distinguished by marginal sutures. Importantly, this suggests that the so-called "hypoparian" suture condition, where the cephalic sutures skirt the margin of the cephalon (Raw 1949), emerged at least twice within Harpetida: once in Harpididae and once again in Harpetidae. Given the number of morphological characters uniting the recognized harpidids, it seems necessary to retain the family Harpididae, though the group currently falls within the entomaspidid grade.

It is not only the harpidids that resolve within the entomaspidid grade. Three taxa previously assigned to the family Harpetidae are shown by these analyses to fall within this grade as well. These taxa-Conococheaguea ovata, Bowmania lassieae, and Heterocaryon vargum — form a small clade within the entomaspidid grade. That these three should resolve here, rather than among the Harpetidae, is perhaps unsurprising given their unusual morphology. 
For example, none of these taxa displays the usual "harpetid brim". Bowmania instead sports a wide fringe of radiating spines (Ludvigsen 1982; Adrain \& Westrop 2004), making it perhaps the most morphologically unusual of all harpetids, while Conococheaguea and Heterocaryon have only a narrow trough (Rasetti 1959; Adrain \& Westrop 2004). Moreover, these taxa lack other key harpetidid synapomorphies, such as a tuberculate eye structure (rather than eye lobes), alae, marginal sutures, and broad, flattened genal prolongations.

The genera Conococheaguea, Bowmania, and Heterocaryon should be removed from Harpetidae and recognized as a separate family. Heterocaryon was once the type for the trilobite family Heterocaryonidae, proposed by Hupé (1953). Though the family is no longer recognized, these findings indicate that the name could be resurrected to describe this new clade of harpetids, which until this point have remained largely in taxonomic limbo (Hupé 1953; Rasetti 1959; Jell \& Adrain 2002). This new incarnation of the family Heterocaryonidae is defined by a few key synapomorphies, including high cephalon convexity and equilateral glabellar lateral margins. Harpetidid Genera-With Conococheaguea, Bowmania, and Heterocaryon recognized as members of the newly resurrected family Heterocaryonidae, Harpetidae is resolved in these analyses as a monophyletic clade. This largest harpetid family includes representatives of nearly a dozen currently recognized harpetid genera. However, the monophyly of several of these genera now appears dubious.

The genus Scotoharpes is evidently polyphyletic. Most species of the putative genus form a loose grouping, with a clade of three taxa—-Scotoharpes" spasski, "Scotoharpes" tatouyangensis, and "Scotoharpes" raaschi-forming a polytomy with two other Scotoharpes species, as well as a substantial clade of other harpetidids. Yet even if these two Scotoharpes"Scotoharpes" loma and Scotoharpes domina (the type species for the genus) - group with the 
others, this grouping would be at best paraphyletic. Moreover, two other supposed Scotoharpes also appear in this analysis and these taxa fall much more basally within Harpetidae, making the genus, as presently defined, certainly polyphyletic. Nor do these two species, "Scotoharpes" latior and "Scotoharpes" consuetus, appear to enjoy a close relationship to one another. Therefore, a natural Scotoharpes does not seem to exist. Some characters that were supposedly diagnostic for Scotoharpes, such as a glabella that is longer than it is wide, deep posterior glabellar furrows, the absence of a larger anterior boss, and the anterior-posterior position of the eyes (Ebach \& McNamara 2002), now appear plesiomorphic for Harpetidae. Others, such as low alae, deep pits demarcating the outer margin of the genal roll, and a flat preglabellar field, appear in some species of the genus but not in all. This finding supports the assessment of Ebach \& McNamara (2002), who noted in passing that Scotoharpes might very well be non-monophyletic and consist of several monophyletic groups, describing the genus as a "dumping ground".

Similarly, the genus Lioharpes also appears to be polyphyletic. Only two species appear in this analysis, but they resolve in a polytomy in the parsimony consensus tree, suggesting that they are either paraphyletic or polyphyletic, and resolve as polyphyletic in the Bayesian tree. As with Scotoharpes, the members of Lioharpes seem to share the features of a generalized harpetid morphology with little to unite them in particular. For example, the radiating ridges found at the genal roll/brim boundary, thought by Fortey and Owens (1997) to be diagnostic for Lioharpes are also seen in other harpetidid genera such as Bohemoharpes and Scotoharpes (Norford 1973; Ebach \& McNamara 2002). Similarly, the narrow alae seen in Lioharpes are less unique than was perhaps supposed; small alae are a feature of some Scotoharpes, Dubhglasina, and Brachyhipposiderus as well, suggesting that this character may in fact be plesiomorphic for Harpetidae (Norford 1973; Ebach \& McNamara 2002). 
The genus Helioharpes has already been identified as a subjective synonym of Harpes by the work of Jell \& Adrain (2002). This study supports this view, in that both of the 'Helioharpes' species included in our phylogenetic analysis independently appear as the sister taxon to separate clades of Harpes trilobites. In fact, it is almost possible, by recognizing the synonymy of Harpes and Helioharpes to discern a monophyletic Harpes within the consensus tree, for both species of 'Helioharpes' and all the recognized Harpes trilobites in this analysis belong to a single clade. However, this clade also contains the genus Dolichoharpes.

Several potential resolutions of this difficulty exist. One is simply to synonymize Dolichoharpes with the genus Harpes. This solution would create a natural Harpes, but may seem unsatisfactory to some, as many Dolichoharpes trilobites have a distinctive appearance that is different from that of other harpetidids (Whittington 1949). In particular, the genal prolongations of Dolichoharpes often appear narrower than those of Harpes, sometimes dramatically so as in the case of Dolichoharpes dentoni (the representative of the genus included in this analysis; see Fig. 1). However, this striking visual change is achieved by a relatively small angular rotation of the genal spines, and Harpes and Dolichoharpes are united by many other, subtler morphological similarities. Anterolaterally directed eye ridges appear to be a synapomorphy of Dolichoharpes and all the putative Harpes in this analysis (Ebach and McNamara 2002). Therefore, it may be worth seriously considering the possibility that all Dolichoharpes trilobites are better thought of as aberrant members of the genus Harpes, or that Harpes may actually comprise multiple recognizable genera. Complicating the issue is that fact that Harpes is another phylogenetic "dumping ground" (Ebach \& McNamara 2002) for otherwise ambiguous harpetid taxa. As such, the genus Harpes may well be genuinely polyphyletic, consisting of two closely related but phylogenetically distinct clades, each also 
closely related to the genus Dolichoharpes. In this case, the clade containing the type species Harpes macrocephalus would be considered the genuine Harpes, while the other may represent a novel genus.

Another possible instance of paraphyly within the family Harpetidae is found in the genus Hibbertia. The two representatives of Hibbertia included in this study appear in the parsimony consensus tree as a paraphyletic grade leading to the problematic Harpes and/or Dolichoharpes clade discussed above. Yet in the Bayesian phylogeny Hibbertia resolves as a monophyletic clade. Further research is needed to fully assess the monophyly of this genus.

All the other recognized harpetidid genera included in this analysis appear to form monophyletic groups. Some of these genera are here represented by only a single species, and so their monophyly has yet to be genuinely tested - such is the case for the genera Kielania, Brachyhipposiderus, and Dubhglasina. Yet others such as Globoharpes and Eskoharpes appear to be well supported, suggesting them to be natural groups. Of these, Eskoharpes is perhaps the most notable, as this clade includes the species "Harpes" neogracilis, lending support to its transfer to Eskoharpes by McNamara et al. (2009).

\section{Disparity in Harpetida}

Sampled Taxa Alone-Three major shifts in harpetid disparity are apparent when disparity analysis is limited to sampled taxa (Fig. 4). The first occurs gradually during the Late Cambrian and into the Ordovician, when the sum of variances increases modestly over time. This may represent the initial diversification of harpetids and would be consistent with the findings of previous researchers (Foote 1997; Hughes et al. 2013) who observed that clades generally morphologically diversify early in their history. 
The second shift in disparity is more abrupt and of greater magnitude. As the group enters the Silurian, disparity falls considerably. This change may be due to the Late Ordovician mass extinction, the first of the five major extinction events of the Phanerozoic, responsible for eliminating an estimated $85 \%$ of marine species (Raup \& Sepkoski 1082; Sheehan 2001). This idea would be consistent with findings suggesting that, during times of biotic crisis, disparity may decline due to a decrease in available ecological habitats and/or an increase in developmental constraints (Gould 1991; Valentine 1995; Zelditch et al. 2003; Thorne 2011; Bapst et al. 2012; Crônier 2013;). Though this phenomenon is not universal (Lupia 1999; Ruta et al. 2013) it nevertheless seems to exist across taxonomic boundaries, having been observed in ichthyosaurs (Thorne et al. 2011), graptoloids (Bapst et al. 2012), phacopid trilobites (Crônier 2013), and now harpetids.

As the Harpetida enters the Devonian, the disparity of the sampled taxa begins to rise again, eventually equaling or even exceeding pre-extinction levels. This is broadly in agreement with the work of Bapst et al. (2012), which found that graptoloid disparity following the Late Ordovician mass extinction increased rapidly after an initial bottleneck, meaning that both harpetid trilobites and graptoloids would have emerged from the Ordovician-Silurian extinction events retaining the capacity for further morphological diversification. Unlike the graptoloids, the recovery of harpetids does not appear to have been a rapid radiation. Rather, harpetid disparity remained low throughout the Silurian. This pattern is in keeping with findings of Rasmussen et al. (2019), which characterize the Silurian as a prolonged recovery interval. Recent work by Sclafani et al. (2019) suggests that extinction during the Late Ordovician may have been random with regard to morphology, which may have facilitated these recoveries of disparity. However, Scalfani et al. (2019) also observed that the disparity of strophomenoid brachiopods 
never fully recovered following the Late Ordovician mass extinction, indicating that responses to the mass extinction were still highly individual.

Studying harpetid morphospace provides additional insights. There are statistically significant differences between morphospace occupation during the Cambrian and during the Ordovician (Table 2), supporting the idea of early morphological diversification. A plot of the first two principal components shows that the group has shifted away from the left edge of visible morphospace, the areas dominated by the harpidids and heterocaryonidids, and expanded into the central and upper right portions of the plot, areas dominated by the family Harpetidae (Fig. 5). Thus the first major shift in disparity appears to have been not only an expansion of morphospace occupation, but also a shift away from more basal morphologies.

A second major shift in morphospace occupation seems to have come at the end of the Ordovician, when harpetid morphospace appears to have contracted significantly in response to the Late Ordovician mass extinction. PERMANOVA testing confirms statistically significant differences between Ordovician and Silurian morphospace occupation (Table 2). The observed loss of disparity (Fig, 4) already implied that the Late Ordovician mass extinction did not merely remove harpetid morphologies at random. Rather, there was a degree of selectivity either to the extinction itself or, more probably, to those taxa that were able to recover in its aftermath (Lamsdell \& Selden 2017; Sclafani et al. 2019). Here it appears that the extinction event was specifically pruning the edges of occupied harpetid morphospace in a pattern consistent with marginal or symmetric selective extinction (Korn et al. 2013). Harpetid morphospace is smaller in the Silurian than in the Ordovician, but the position of the centroid changes little (Fig. 5).

Recovery from this loss was slow and it was not until the Devonian that harpetid morphospace occupation began to seriously recover. This recovery likely accounts for the 
statistically significant difference between Silurian and Devonian morphospace occupation (Table 2). Visually, the group first expanded upwards and to the right, until it occupied a roughly similar area to that held in the Late Ordovician before the mass extinction event (Fig. 5). However, during the Late Devonian the group underwent another shift, one not readily apparent by looking at measures of disparity alone. While the total area of visible morphospace occupied remained similar in size, it was now confined to the lower right-hand portion of the plot, an area of morphospace never before colonized by Harpetida (Fig. 5). These shifts suggest that harpetids as a group were still very morphologically dynamic, even following the loss of disparity during the Late Ordovician mass extinction (sensu Crônier 2013). However, the group never returned to any of the areas it held during the Cambrian, perhaps suggesting limits to this dynamicity.

Phylogenetically Corrected Sample-Phylogenetically corrected disparity analyses of Harpetida show that disparity within the order was less subject to change than would be implied by analyses using sampled taxa alone, suggesting that periods of low sampling may account for many of the tentative trends described above. In these corrected analyses, the sum of ranges and sum of variance (Fig. 6; Fig. 7) both show only a modest peak in harpetid disparity during the Ordovician. This early peak may represent the initial diversification of harpetids, which would be consistent with the work of previous researchers (Foote 1997; Hughes et al. 2013) who found that clades generally morphologically diversify early in their history.

No abrupt Late Ordovician decline is seen in disparity analyses of Harpetida including reconstructed ancestors (Fig. 6; Fig. 7). Instead, disparity appears to decreases slowly and steadily from the Late Ordovician onward. The rate of decrease does not significantly increase during the Late Ordovician mass extinction. This finding closely resembles that of Ruta et al. (2013), which showed that amonodont therapsid disparity decreased steadily over time, relatively 
unaffected by the end-Permian mass extinction. More broadly, these findings might be said to agree with those of Lupia et al. (1999), which showed that the rate and character of change in the disparity of Late Cretaceous angiosperms was not altered by the end-Cretaceous mass extinction, and with Zelditch et al. (2003), whose work with piranha suggested that disparity tends naturally to decay over time. This scenario also shows that disparity and diversity were significantly decoupled in Harpetida, which supports the idea that disparity and diversity are frequently decoupled (Foote 1993; Lupia 1999; Thorne et al. 2011; Hopkins 2013; Ruta et al. 2013).

The fact that harpetids in particular were relatively unaffected by the Late Ordovician mass extinction may perhaps be explained by their life history strategy. Harpetid larvae are thought to have been benthic rather than planktonic (Chatterton \& Speyer 1989). In this they resemble sphaerexochine trilobites, which also had benthic larvae and were largely unaffected by the Late Ordovician mass extinction. Both of these examples, agree with the general findings of Chatterton and Speyer (1989), who concluded that trilobites with benthic larvae were generally far more resilient to the Late Ordovician mass extinction.

Despite their resilience, harpetid disparity remained low or continued to fall from the Late Ordovician onward, until the group went extinct at the end of the Devonian; no long-term recovery of disparity could be discerned in the phylogenetically corrected data (Fig. 6; Fig. 7). This finding is again consistent with Ruta et al. (2013) and also with Thorne et al. (2011), which observed that ichthyosaurs failed to fully recover their former disparity following the endTriassic mass extinction. As such, harpetids' case might be considered analogous to that of a "Dead Clade Walking" or DCW (Jablonski 2002), a clade that fails to recover in terms of taxonomic diversity following a mass extinction. 
By including reconstructed ancestors in harpetid morphospace, new patterns may be discerned (Fig. 8). Early in its history, Harpetida shifts away from occupying the lower right corner of visible morphospace and expands into the left-hand and upper central regions (Fig. 8). PERMANOVA testing confirms that Cambrian and Ordovician harpetid morphospace were statistically significantly different (Table 3). These changes support an assessment of early diversification and moreover show that harpetids were very morphologically dynamic during their early history. However, this dynamicity seems to wane somewhat as the order enters the Silurian. Although Silurian and Ordovician harpetid morphospace remain statistically different, the significance of this difference has declined (Table 3). In particular, the area of morphospace occupied during the Late Ordovician is quite similar to that occupied throughout the Silurian. In both cases, occupation is distributed almost evenly across the left-hand side of a plot of the first two principal components (Fig. 8). Yet the sum of variance does gradually decline (Fig. 6; Fig. 7), even while overall morphospace occupation changes little (Fig. 8). From this it seems clear that morphologies were being removed in a random, non-selective fashion (Korn et al. 2013). These losses were gradual, rather than occurring suddenly at the end of the Ordovician, indicating that harpetid morphospace was generally agnostic to the Late Ordovician mass extinction.

During the Devonian harpetids shift from occupying the left side of visible morphospace evenly to being concentrated in the lower left corner, with the emergence of Eskoharpes and Globoharpes in the Late Devonian representing the first real burst of morphological innovation since the Ordovician (Fig. 8). However the scale of this shift in visible morphospace is relatively small (Fig. 8) and overall measures of disparity continue their slow decline (Fig. 6; Fig. 7). Harpetida loses access to the upper reaches of morphospace and never regains any of regions it 
held prior to the end of the Ordovician (Fig. 8). From this, it seems evident that harpetids became less morphologically dynamic over their history. Other researchers have observed that groups emerge from mass extinction events lacking the ability morphologically or ecologically diversify (Jablonski 2002; Thorne et al. 2011; Ruta et al. 2013). It is possible that, although the Late Ordovician mass extinction had little immediate impact on harpetid disparity, the biotic crisis nevertheless permanently damaged Harpetida's ability to generate new morphologies. Despite this, the innovation seen in Eskoharpes and the closely related Globoharpes in the Late Devonian indicates that the order had not wholly lost its ability to morphologically diversify.

The Structure of Harpetid Morphospace-The phylogenetic signal within harpetid morphospace appears strong. Statistically significant differences are found between the areas of morphospace occupied by all four putative harpetid families (Table 4). Of these, three families also group well along the first two principal component axes, each occupying a distinct area of visible morphospace (Fig. 9). The fourth is the polyphyletic Entomaspididae, which—perhaps unsurprisingly — does not group well in visible morphospace (Fig. 9) and also shows the least statistically significant difference with another harpetid family, in this case Harpididae (Table 4).

PERMANOVA testing shows that harpetids associated with particular paleoenvironments also generally have significantly different areas of morphospace occupation (Table 5). This finding is consistent with the work of Hopkins (2014), which revealed strong environmental structuring to the disparity of trilobites. However, for Harpetida, this ecological component to morphospace structure is not well illustrated in plots of the first two principal component axes. Elliptical partitions intended to designate different ecological groups overlap widely, revealing little obvious signal to the eye (Fig. 10). This indicates that the variation between these ecological groups is limited to the less informative principal components. When contrasted with 
the observed (and more statistically significant) differences between harpetid families described above, it seems clear that phylogeny exerts a stronger control on harpetid morphospace-and therefore harpetid morphology—-than does ecology.

One pattern that can be observed by looking at Harpetida through an ecological perspective, is the repeated ability of distantly related harpetids to colonize or recolonize similar habitats, often despite having widely differing morphologies (Fig. 10). A prime example of this phenomenon is seen in the genus Bowmania. Like many harpetids, Bowmania is associated with a subtidal shelf environment. However, it is not closely related to the other harpetids that share this environmental association, belonging to the family Heterocaryonidae rather Harpetidae (Fig. 3) and in visible morphosapce it plots quite distantly from them (Fig. 10). This may suggest that Bowmania indeed found a different solution to the same ecological problem, using a fringe of radiating spines instead of the usual harpetid brim. Another example is the genus Eskoharpes and the closely related Globoharpes. These Late Devonian representatives of Harpetida are both associated with marginal slope environments (McNamara et al. 2009), yet their morphologies differ strongly from those of the harpidids and basal harpetidids that previously colonized this environment.

\section{SYSTEMATIC PALEONTOLOGY}

Class TRILOBITA Walch, 1771

Subclass LIBROSTOMA Fortey, 1990

Order HARPETIDA Whittington, 1959

Diagnosis. Cephalon subsemicircular to ovate in outline, with long genal prolongations or spines. Glabella convex, narrowing forward, with up to three pairs of lateral glabellar furrows, 
preoccipital pair isolating triangular lateral lobes; occipital ring convex; preglabellar field sloping outward and downward to flat or upwardly concave fringe or bilamellar border; alae may be present; prominent eye lobes or tubercles centrally located on genae, with strong eye ridges and in some forms with genal ridges also; sutures commonly marginal except on dorsal side at genal angles, and (in genera with eye lobes) where sections of sutures run inward close together. Thorax with 12 or more segments; axis convex; pleurae flat, with broad pleural furrows. Pygidium short, subtriangular or elongate, with convex axis. Radiating, anastomosing genal caecae may be present on genae and preglabellar field, and extending onto fringe; external surface of cephalon may be tuberculate or granulose. (modified from Fortey \& Owens 1997). Range. Upper Cambrian to Upper Devonian

Family ‘ENTOMASPIDIDAE’ Ulrich, 1931

Type genus. Entomaspis Ulrich, 1931

Included genera. Baikadamaspis Ergaliev 1980, Entomaspis Ulrich 1931, Notchpeakia Adrain \& Westrop 2006

Diagnosis. Exoskeleton small. Cephalon semicircular, characterized by anterior and posterior sections of facial sutures close to each other, both directed outward-backward; librigenae fused together through doublure, dorsally consisting of narrow strips connecting eyes to margin and genal spines (Fortey \& Owens 1997).

Range. Upper Cambrian to Lower Ordovician

Remarks. The family Entomaspididae is resolved in the present analyses as polyphyletic and needs to be redefined so as to be monophyletic. The family is here used to denote various basal harpetids, with the quote marks denoting polyphyly.

Family HETEROCARYONIDAE Hupé 1953 
Type genus. Heterocaryon Raymond, 1937

Included genera. Bowmania Walcott 1925; Conococheaguea Rasetti 1959; Heterocaryon Raymond, 1937.

Diagnosis. Angle of cephalic curvature greater than 90 degrees. Yoked librigenae, but lacking true bilamellar fringe. Facial sutures directed outward and forward. Small eye lobes, diverging posteriorly, with eye ridges anterolaterally directed. High cephalon convexity and equilateral glabellar lateral margins. Highly convex genae. Lacking alae. Narrow, rounded genal prolongations (i.e. spines). Pygidium of four to eight segments.

Range. Upper Cambrian

Remarks. This family level name has been resurrected to describe a clade including the genus Heterocaryon and two other taxa previously assigned to Harpetidae but whose unusual morphology otherwise placed them within the entomaspidid grade in these phylogenetic analyses.

Family HARPIDIDAE Whittington, 1950

Type genus. Harpides Beyrich, 1846

Included genera. Chencunia Qiu 1984, Dictyocephalites Bergeron 1895, Harpides Beyrich 1846, Kitatella Petrunina 1960, Loganopeltis Rasetti 1943, Loganopeltoides Rasetti 1945, Metaharpides Pillet \& Courtessole 1980, Paraharpides Pillet \& Courtessole 1980, Pscemiaspis Abdullaev 1970.

Diagnosis. Cephalic border not sharply set off from convex genae and preglabellar field; alae small, semicircular; facial sutures marginal, or with parallel anterior and posterior sections running close to each other and directed anterolaterally from eye tubercles to margin; genal caeca radiating over cheek lobes and in some extending onto cephalic border. Hypostome 
subrectangular, length ( $\mathrm{sag}$.) equal to that of glabella. Thorax with 20 or more segments; axis narrow; long (tr.) pleurae curving back at outer part may be extended into spines, with deep pleural furrows and convex posterior bands. (Fortey \& Owens 1997).

Range. Upper Cambrian to Lower Ordovician.

Family HARPETIDAE Hawle and Corda, 1847

Type genus. Harpes Goldfuss, 1839

Included genera. Bohemoharpes Vanek 1963, Brachyhipposiderus Jell 1985, Dolichoharpes

Whittington 1949, Dubhglasina Lamont 1948, Eoharpes Raymond 1905, Harpes Goldfuss 1939, Hibbertia Jones and Woodward 1898, Kathrynia Westrop 1986, Kielania Vanek 1963, Lioharpes Whittington 1950, Paleoharpes Lu \& Chien 1978, Scotoharpes Lamont 1948. Diagnosis. Eye tubercles each with two lenses; semicircular alae adjacent to posterior glabellar lobes; bilamellar fringe with opposed pits in outer surfaces, genal rolls steeply sloping, brim gently sloping, with stout girder on lower lamella separating these two parts, flattened prolongations of fringe varying in length; cephalic suture skirts marginal band of fringe. Hypostome pear-shaped in outline, with ovate middle body, large anterior, small posterior, and wings. Thorax with 12 to 29 segments, pleurae bent down at tips. Pygidium small, short (sag.), triangular, with few segments. External surface of glabella and genae with raised ridges in reticulate pattern, tuberculate, or smooth; minute tubercles on fringe between pits and marginal band, on internal rim, and elsewhere. (modified from Fortey \& Owens 1997).

Range. Lower Ordovician to Upper Devonian.

\section{CONCLUSIONS}


The primary work of this study has been to evaluate the morphology and evolution of harpetid trilobites, a group that had long been easily recognized but poorly understood. This study provides strong support for harpetid monophyly. Two of the three existing harpetid families have also been found to be monophyletic, while the third — Entomaspididae — has been found not to be a natural group. In addition, support has been found for the monophyly of a fourth harpetid family, the Heterocaryonidae, which unites several previously problematic taxa. At a finer taxonomic scale, several harpetid genera are found to be poorly supported (e.g. Scotoharpes, Lioharpes), while several others are found to be well supported (e.g. Eskoharpes, Globoharpes). Importantly, marginal sutures - a key innovation within Harpetida (Rasetti 1945; Ebach \& McNamara 2002) — are found to have arisen on at least two separate occasions within the order.

Harpetid disparity is first found to rise, as the group diversifies and shifts within morphospace. Disparity then falls, possibly in an abrupt drop associated with the Late Ordovician mass extinction, but more likely in a slow decline throughout the Silurian and Devonian. A final burst of morphological innovation in the Late Devonian is unable to stave off the group's final extinction. These findings demonstrate that mass extinction events may have a complex impact that plays out over many millions of years, shaping the morphologies of even those species able to defy death by surviving the worst calamities in the history of life on Earth.

\section{LITERATURE CITED}

Adrain, J.M. 2011. Class Trilobita. Animal Biodiversity: Zootaxa. 3148: 104-109.

Adrain, J. M., G. D. Edgecombe, R. A. Fortey, O. Hammer, J. R. Laurie, T. McCormick, A. 
W. Owen, B. G. Waisfeld, B. D. Webby, S. R. Westrop, and Z. Zhou. 2004. Trilobites. Pp. 231-254 in B. D. Webby, F. Paris, M. L. Droser, and I. G. Percival, eds. The great Ordovician biodiversification event. Columbia University Press, New York.

Adrain, J. M. \& Westrop, S.R. 2004. A Late Cambrian (Sunwaptan) silicified trilobite fauna from Nevada. Bulletins of American Paleontology. 365: 5-56.

Adrain, J. M. \& Westrop, S.R. 2006. Notchpeakia, a new genus of Upper Cambrian (Sunwaptan) “entomaspidid" trilobites. Journal of Paleontology. 80(6): 1152-1171.

Anderson, M.J. 2017. Permutational Multivariate Analysis of Variance (PERMANOVA). N. Balakrishnan, T. Colton, B. Everitt, W. Piegorsch, F. Ruggeri, J. Teugels, eds. Wiley StatsRef: Statistics Reference Online. Online: John Wiley \& Sons, Ltd.

Armstrong, R.A. 2014. When to use the Bonferroni correction. OPO. 34(5): 502-508.

Bambach, R.K., Knoll, A.H., \& Wamg, S.C. 2004. Origination, extinction, and mass depletions of marine diversity. Paleobiology. 30: 522-542.

Bapst, D.W., Bullock, P.C., Melchin, M.J., Sheets, H.D., \& Mitchell, C.E. 2012. Graptoloid diversity and disparity became decoupled during the Ordovician mass extinction. PNAS. 109: $3428-33$.

Brenchley, P. J., G. A. Carden, L. Hints, D. Kaljo, J. D. Marshall, T. Martma, T. Meidla, and J. Nõlvak. 2003. High resolution stable isotope stratigraphy of Upper Ordovician sequences: constraints on the timing of bioevents and environmental changes associated with mass extinction and glaciation. Geological Society of American Bulletin 115:89104. 
Brusatte, S.L., Montanari, S., Hong-yu Yi, \& Norell, M.A. 2011. Phylogenetic corrections for morphological disparity analysis: new methodology and case studies. Paleobiology. 37: 1-22.

Chatterton, B.D.E. \& Speyer, S.E. 1989. Larval ecology, life history strategies, and patterns of extinction and survivorship among Ordovician trilobites. Paleobiology. 15: 118-132.

Congreve, C.R. 2008. The End Ordovician; an ice age in the middle of a greenhouse. In: Mass Extinction. Springer, Berlin, Heidelberg.

Congreve, C.R. 2013. Cladal Turnover: the end-Ordovician as a large-scale analogue of species turnover. Palaeontology. 56(6): 1285-1296.

Congreve, C.R. 2013. Evolutionary patterns of trilobites across the end Ordovician mass extinction. University of Kansas.

Congreve, C.R., Falk, A.R., \& Lamsdell, J.C. 2018. Biological hierarchies and the nature of extinction. Biological Reviews. 93(2): 811-826.

Congreve, C.R., Krug, A.Z., \& Patzkowsky, M.E. 2019. Evolutionary and biogeographical shifts in response to the Late Ordovician mass extinction. Palaeontology. 62(2): 267-285.

Congreve, C.R. \& Lamsdell, J.C. 2016. Implied weighting and its utility in palaeontological datasets: a study using modelled phylogenetic matrices. Palaeontology. 59(3): 447-462.

Crônier, C. 2007. Larval morphology and ontogeny of an Upper Devonian phacopid: Nephranops from Thuringia, Germany. Journal of Paleontology, 81: 684-700.

Crônier, C. 2010. Varied development of trunk segmentation in three related Upper Devonian phacopine trilobites. Historical Biology. 22: 341-347.

Crônier, C. 2013. Morphological disparity and development patterning: contribution of phacopid trilobites. Palaeontology. 56(6): 1263-1271. 
Crônier, C., Auffray, J.C., \& Courville, P. 2005. A quantitative comparison of the ontogeny of two closely-related Upper Devonian phacopid trilobites. Lethaia, 38: 123-135.

Crônier, C., Bignon, A. and Francois, A. 2011. Morphological and ontogenetic criteria for defining a trilobite species: the example of Siluro-Devonian Phacopidae. Comptes Rendus Palevol. 10: 143-153.

Crônier, C. \& Courville, P. 2003. Variations du rythme du developpement chez les trilobites Phacopidae neodevoniens. Comptes Rendus Palevol, 2: 577-585.

Crônier, C. \& Fortey R. 2006. Morphology and ontogeny of an Early Devonian phacopid trilobite with reduced sight from southern Thailand. Journal of Paleontology, 80: 529536.

Dai, T. \& Zhang, X. 2013. Ontogeny of the redlichiid trilobite Eoredlichia intermedia from the Chengjiang Lagerstatte, lower Cambrian, southwest China. Lethaia. 46: 262273.

Dirzo, R., Young, H.S., Galetti, M., Ceballos, G., Isaac, N.J.B., \& Collen, B. 2014. Defaunation in the Anthropocene. Science. 345: 401-406

Dommergues, J., Luairn, B., \& Meister, C. 1996. Evolution of ammonoid morphospace during the Early Jurassic radiation. Paleobiology. 22(2): 219-240.

Drosser, M.L., Bottjer, D.J., Sheehan, P.M., \& McGhee, G.R. 2000. Decoupling of taxonomic and ecologic severity of Phanerozoic marine mass extinctions. Geology. 28 (8): 675-678.

Dunn, O.J. 1961. Multiple Comparisons among Means. Journal of the American Statistical Association 293(56): 52-64.

Ebach, M.C. \& McNamara, K.J. 2002. A systematic revision of the family Harpetidae (Trilobita). Records of the Western Australian Museum. 21:135-67. 
Fatka, O., Mergal, M., \& Budil, P. 2013. Preservation of the digestive structures in Harpides (Trilobita) from the Lower Ordovician of the Barrandian area (Czech Republic). Neues Jahrbuch für Geologie und Paläontologie. n/a: 1-15.

Finnegan, S., Bergmann, K., Eiler, J.M., Jones, D.S., Fike, D.A., Eisenman, I., Hughes, N.C., Tripati, A.K., \& Fischer, W.W. 2011. The magnitude and duration of Late OrdovicianEarly Silurian glaciation. Science. 331: 903-906.

Finnegan, S., Heim, N.A., Peters, S.E., \& Fischer, W.W. 2012. Climate change and the selective signature of the Late Ordovician mass extinction. PNAS. 109(18): 6829-6834.

Finnegan, S., Rasmussen, C.M.Ø, \& Harper, D.A.T. 2016. Biogeographic and bathymetric determinants of brachiopod extinction and survival during the Late Ordovician mass extinction. Proceedings of the Royal Society B. 283: 1-9.

Fitch, W.M. 1997. Toward Defining the Course of Evolution: Minimum Change for a Specific Tree Topology. Systematic Zoology. 20(4): 406-416.

Foote, M. 1991. Analysis of Morphological Data. The Paleontological Society Papers. 4: 59-86.

Foote, M. 1992. Paleozoic record of morphologica diversity in blastozoan echinoderms. PNAS. 89(16): 7325-7329.

Foote M. 1993. Discordance and concordance between morphological and taxonomic diversity. Paleobiology. 19: $185-204$.

Foote, M. 1994. Morphological disparity in Ordovician-Devonian crinoids and the early saturation of morphological space. Paleobiology. 20(3): 320-344.

Foote, M. 1995. Morphological Diversification of Paleozoic Crinoids. Paleobiology. 21(3): 273299.

Foote, M. 1997. The evolution of morphological diversity. Annual Review of Ecological 
Systematics. 28: 129-152.

Foote, M. 1999. Morphological diversity in the evolutionary radiation of Paleozoic and postPaleozoic crinoids. Paleobiology. 25: 1-115.

Forety, R.A. 1990. Ontogeny, hypostome attachment and trilobite classification. Palaeontology. 33(3): 529-576.

Fortey, R.A., \& Owens, R.M. 1997. Evolutionary history. Pp. 250-287 in R. L. Kaesler, ed. Treatise on invertebrate paleontology, part O, Arthropoda 1, Trilobita, Revised. Volume 1. Geological Society of America and University of Kansas. Boulder, Colorado, and Lawrence, KS.

Fortey, R.A., \& Owens, R.M. 1999. Feeding habits in trilobites. Palaeontology. 42(3): 429-465.

Goloboff, P.A., Farris, J.S., \& Nixon, K.C. 2008. TNT, a free program for phylogenetic analysis. Cladistics. 24(5): 774-786.

Gould, S.J. 1991. The disparity of the Burgess Shale arthropod fauna and the limits of cladistics analysis: why we must strive to quantify morphospace. Paleobiology. 17(4): 411-423. Halliday, T.J.D. \& Goswami, A. 2015. Eutherian morphological disparity across the endCretaceous mass extinction. Biological Journal of the Linnean Society. 118: 152-168. Harper, D.A.T., Hammarlund, E. U., \& Rasmussen, C. M. Ø. 2014. End Ordovician extinctions: A coincidence of causes. Gondwana Research. 25: 1294-1307.

Hetherington, A. J., Sherratt, E., Ruta, M., Wilkinson, M., Deline, B., \& Donoghue, P. C. J. 2015. Do cladistic and morphometric data capture common patterns of morphological disparity? Palaeontology. 58(3): 393-399.

Holland, S.M. \& Patzkowsky, M.E. 2015. The stratigraphy of mass extinction. Palaeontology. 58(5): 903-924. 
Hopkins, M.J. 2013. Decoupling of taxonomic diversity and morphological disparity during decline of the Cambrian trilobite family Pterocephaliidae. Journal of Evolutionary Biology. 26: 1665-1676.

Hopkins, M.J. 2014. The environmental structure of trilobite morphological disparity. Paleobiology. 40(3): 352-373.

Hopkins, M.J. \& Lidgard, S. 2012. Evolutionary mode routinely varies among morphological traits within fossil species lineages. PNAS. 109(50): 20520-20525.

Huelsenbeck, J.P. \& Ronquist, F. 2001. MRBAYES: Bayesian inference of phylogenetic trees. Bioinformatics. 17(8): 754-755.

Hughes, M., Gerber, S., \& Wills, M.A. 2013. Clades reach highest morphological disparity early in their evolution. PNAS. 110(34): 13875-13879.

Hughes, N.C. 2007. The evolution of trilobite body patterning. Annual Review of Earth and Planetary Sciences. 35: 401-434.

Jablonski, D. \& Raup, D.M. 1995. Selectivity of end-Cretaceous marine bivalve extinctions. Science. 268: 389-391.

Jablonski, D. 2001. Lessons from the past: Evolutionary impacts of mass extinctions. PNAS. 98(10): 5393-5398.

Jablonski, D. 2002. Survival without recovery after mass extinctions. PNAS. 99(12): 8139-8144.

Jell, P.A. \& Adrain, J.M. 2002. Available generic names for trilobites. Memoirs of the Queensland Museum 48(2): 331-553.

Korn, D., Hopkins, M.J., \& Walton, S.A. 2013. Extinction space: a method for the quantification and classification of changes in morhopsace across extinction boundaries. Evolution. 67(10): 2795-2810. 
Lamsdell, J.C. (2019, February 20). Personal interview.

Lamsdell, J.C. \& Selden, P.A. 2014. Phylogenetic support for the monophyly of proetide trilobites. Lethaia. n/a: 1-12.

Lamsdell, J.C. \& Selden, P.A. 2017. From success to persistence: Identifying an evolutionary regime shift in the diverse Paleozoic aquatic arthropod group Eurypterida, driven by the Devonian biotic crisis. Evolution. 71: 95-110.

Lewis, P.O. 2001. A likelihood approach to estimating phylogeny from discrete morphological character data. Systematic Biology. 50(6): 913-925.

Lofgren, A.S., Plotnick, R.E., \& Wagner, P.J. 2003. Morphological diversity of Carboniferous arthropods and insights on disparity patterns through the Phanerozoic. Paleobiology 29:349-368.

Lupia, R. 1999. Discordant morphological disparity and taxonomic diversity during the Cretaceous angiosperm radiation: North American pollen record. Paleobiology. 25(1): 128.

Maddison, W. P. \& Maddison, D.R. 2018. Mesquite: a modular system for evolutionary analysis. Version 3.51 http://www.mesquiteproject.org

McClain, C.R. 2005. Bathymetric patterns of morphological disparity in deep sea gastropods from the western North Atlantic Basin. Evolution. 59(7): 1492-1499.

McGhee, G.R., Sheehan, P.M., Bottjer, D.J., \& Droser, M.L. 2004. Ecological ranking of Phanerozoic biodiversity crises: ecological and taxonomic severities are decoupled. Palaeogeography, Palaeoclimatology, Palaeoecology. 211: 289-297. 
McGhee, G.R., Sheehan, P.M., Bottjer, D.J., \&Droser, M.L. 2012. Ecological ranking of Phanerozoic biodiversity crises: The Serpukhovian (early Carboniferous) crisis had a greater ecological impact than the end-Ordovician. Geology. 40 (2): 147-150.

McNamara, K.J., Feist, R., \& Ebach, M.C. 2009. Patterns of evolution and extinction in the last harpetid trilobites during the late Devonian (Frasnian). Palaeontology. 52(1): 11-33.

Norford, B.S. 1973. Lower Silurian species of the trilobite Scotoharpes from Canada and northwestern Greenland. Contributions to Canadian Paleontology. 1: 9-25.

Palmer, A.R. 1954. The faunas of the Riley Formation in central Texas. Journal of Paleontology. 28(6): 709-786.

Pearson, K. 2017. Experimental biomechanics of trinucleid fringe pits (Trilobita). (Honor's thesis). Oberlin College, OH, United States.

Qiu, H. 1984. Trilobites from the Upper Cambrian Tangcun Formation in Jingxian, southern Anhui. Acta Palaeontologica Sinica 23(3):329-341

Rasetti, F. 1945. Evolution of the facial sutures in the trilobites Loganopeltoides and Loganopeltis. American Journal of Science. 243(1): 44-50.

Rasetti, F. 1952. Cephallic sutures in the Upper Cambrian trilobite Entomaspis. Journal of Paleontology. 26(5): 797-802.

Rasetti, F. 1959. Trempealeauian trilobites from the Conococheague, Frederick, and Grove Limestones of the Central Appalachians. Journal of Paleontology. 33(3): 375-398.

Rasmussen, C.M.Ø., Kröger, B., Nielsen, M.L., and Colmenar, J. 2019. Cascading trend of Early Paleozoic marine radiations paused by Late Ordovician extinctions. PNAS. n/a: 1-7. Raup, D.M. 1992. Extinction: bad genes or bad luck? New York, New York: W.W. Norton. 
Raup, D.M. \& Sepkoski, J.J. 1982. Mass extinctions in the marine fossil record. Science. 215: 1501-1503.

Raw, F. 1949. Facial sutures in the (hypoparian) trilobites Loganopeltoides and Loganopeltis, and the validity of these genera. Journal of Paleontology. 23(5): 510-514.

Robison, R.A. \& Babcock, L.E. 2011. Systematics, paleobiology, and taphonomy of some exceptionally preserved trilobites from Cambrian lagerstätten of Utah. Paleontological Contributions. 5: 1-47.

Roy, K. \& Foote, M. 1997. Morphological approaches to measuring biodiversity. Trends in Ecology \& Evolution.12(7): 277-281.

Ruta, M., Angielczyk, K.D., Fröbisch, J., \& Benton, M.J. 2013. Decoupling of morphological disparity and taxic diversity during the adaptive radiation of anomodont therapsids. Proceedings of the Royal Society B. 280: 1-9.

Sclafani, J.A., Congreve, C.R., Krug, A.Z., \& Patzkowsky, M.E. 2019. Effects of mass extinction and recovery dynamics on long-term evolutionary trends: a morphological study of Strophomenida (Brachiopoda) across the Late Ordovician mass extinction. Paleobiology. 44(4): 603-619.

Sepkoski, J.J. 1996. Patterns of Phanerozoic extinction: a perspective from global data bases. Global Events and Event Stratigraphy in the Phanerozoic. In: Walliser O.H. (eds) Global Events and Event Stratigraphy in the Phanerozoic. Springer, Berlin, Heidelberg. 35-51.

Sheehan, P.M. 1973. The relation of Late Ordovician glaciation to the Ordovician-Silurian changeover in North American brachiopod faunas. Lethaia. 6(2): 147-154.

Sheehan, P.M. 2001. The late Ordovician mass extinction. Annual Review of Earth and Planetary Sciences. 29: 331-364. 
Swofford, \& Olsen, 1990. Phylogeny reconstruction. Pp. 411-501 in D. M. Hillis

and C. Moritz, eds. Molecular systematics. Sinauer Associates, Sunderland, MA.

Sundberg, F.A. 1996. Morphological diversification of Ptychopariida (Trilobita) from the Marjumiid biomere (Middle and Upper Cambrian). Paleobiology. 22(1): 49-65.

Thorne, P.M., Ruta, M., \& Benton, M.J. 2011. Resetting the evolution of marine reptiles at the Triassic-Jurassic boundary. PNAS. 108: 8339-8344.

Valentine, J.W. 1995. Why no new phyla after the Cambrian? Genome and ecospace hypotheses revisited. Palaios, 10: 190-194.

Villier, L. and Eble, G. J. 2004. Assessing the robustness of disparity estimates: the impact of morphometric scheme, temporal scale, and taxonomic level in spatangoid echinoids. Paleobiology. 30: 652-665.

Wesley-Hunt, G. D. 2005. The morphological diversification of carnivores in North America. Paleobiology. 31: 35-55.

Westrop, S.R. 1992. Upper Cambrian (Marjuman-Steptoean) trilobites from the Port au Port Group, Western Newfoundland. Journal of Paleontology. 66(2): 228-255.

Whittington, H.B. 1949. Dolichoharpes and the origin of the harped fringe. American Journal of Science. 247(4): 276-285.

Whittington, H.B. 1959: Silicified Middle Ordovician trilobites: Remopleuridae, Trinucleidae, Raphiophoridae, Endymioniidae. Bulletin of the Museum of Comparative Zoology 121: $371-496$.

Wills, M.A. 1998. Crustacean disparity through the Phanerozoic: comparing morphological and stratigraphic data. Biol. J. Linn. Soc. 65: 455-500.

Wills, M.A., Briggs, D.E.G., \& Fortey, R.A. 1994. Disparity as an evolutionary index: a 
comparison of Cambrian and Recent arthropods. Paleobiology. 20(2): 93-130.

Wright, A.M. \& Hillis, D.M. 2014. Bayesian analysis using a simple likelihood model outperforms parsimony for estimation of phylogeny from discrete morphological data. PLOS One. 9(10): 1-6.

Xianguang Hou, Clarkson, E.N. K., Jie Yang, Xiguang Zhang, Guangqing Wu \& Zibo Yuan. 2008. Appendages of early Cambrian Eoredlichia (Trilobita) from the Chengjiang biota, Yunnan, China. Earth and Environmental Science Transactions of the Royal Society of Edinburgh. 99: 213-223.

Young, M.T., Brusatte, S.L., Ruta, M., \& De Andrade, M.B. 2010. The evolution of Metriorhynchoidea (Mesoeucrocodylia, Thalattosuchia): an integrated approach using geometric morphometrics, analysis of disparity, and biomechanics. Zool. J. Linn. Soc. 158:801-859.

Zelditch, M.L., Sheets, H.D. \& Fink, W.L. 2003. The ontogenetic dynamics of shape disparity. Paleobiology. 29: 139-156. 


\section{FIGURES \& TABLES}

\begin{tabular}{|c|c|}
\hline Genus & Included \\
\hline Baikadamaspis & $\mathrm{Y}$ \\
\hline Bohemoharpes & $\mathrm{Y}$ \\
\hline Bowmania & $\mathrm{Y}$ \\
\hline Brachyhipposiderus & $\mathrm{Y}$ \\
\hline Chencunia & $\mathrm{N}$ \\
\hline Conococheaguea & $\mathrm{Y}$ \\
\hline Dictyocephalites & $\mathrm{N}$ \\
\hline Dolichoharpes & $\mathrm{Y}$ \\
\hline Dubhglasina & $\mathrm{Y}$ \\
\hline Entomaspis & $\mathrm{Y}$ \\
\hline Eoharpes & $\mathrm{Y}$ \\
\hline Eskoharpes & $\mathrm{Y}$ \\
\hline Globoharpes & $\mathrm{Y}$ \\
\hline Harpes & $\mathrm{Y}$ \\
\hline Harpides & $\mathrm{Y}$ \\
\hline Heterocaryon & $\mathrm{Y}$ \\
\hline Hibbertia & $\mathrm{Y}$ \\
\hline Kathrynia & $\mathrm{N}$ \\
\hline Kielania & $\mathrm{Y}$ \\
\hline Kitatella & $\mathrm{N}$ \\
\hline Lioharpes & $\mathrm{Y}$ \\
\hline Loganopeltis & $\mathrm{Y}$ \\
\hline Loganopeltoides & $\mathrm{Y}$ \\
\hline Metaharpides & $\mathrm{N}$ \\
\hline Notchpeakia & $\mathrm{Y}$ \\
\hline Palaeoharpes & $\mathrm{N}$ \\
\hline Paraharpides & $\mathrm{N}$ \\
\hline Pscemiaspis & $\mathrm{N}$ \\
\hline Scotoharpes & $\mathrm{Y}$ \\
\hline & \\
\hline & \\
\hline
\end{tabular}

Table 1: Recognized harpetid genera included or excluded from these analyses. 


\begin{tabular}{|l|l|l|l|l|}
\hline & Cambrian & Ordovician & Silurian & Devonian \\
\hline Cambrian & - & 7.511 & 10.01 & 9.593 \\
\hline Ordovician & 0.0006 & - & 4.628 & 4.23 \\
\hline Silurian & 0.0006 & 0.0006 & - & 5.682 \\
\hline Devonian & 0.0006 & 0.0006 & 0.0006 & - \\
\hline
\end{tabular}

Table 2: PERMANOVA test results of Harpetida, sampled taxa only (Permutation N: 9999, Total sum of squares: 9105, Within-group sum of squares: 7336, F: 6.994, p (same): 0.0001) for statistical differences between taxa for each of the four period-level time bins based on PCO analyses. Values in regular font are for the Bonferroni corrected $p$-values, those in italics are the raw $\mathrm{F}$ values.

\begin{tabular}{|l|l|l|l|l|}
\hline & Cambrian & Ordovician & Silurian & Devonian \\
\hline Cambrian & - & 16.09 & 26.03 & 28.32 \\
\hline Ordovician & 0.0006 & - & 3.613 & 8.482 \\
\hline Silurian & 0.0006 & 0.0012 & - & 5.626 \\
\hline Devonian & 0.0006 & 0.0006 & 0.0006 & - \\
\hline
\end{tabular}

Table 3: PERMANOVA test results of Harpetida, sampled taxa and reconstructed ancestors (Permutation N: 9999, Total sum of squares: 9731, F: 13.6, p (same): 0.0001) for statistical differences between taxa for each of the four period-level time bins based on PCO analyses. Values in regular font are for the Bonferroni corrected $p$-values, those in italics are the raw $\mathrm{F}$ values.

\begin{tabular}{|l|l|l|l|l|}
\hline & Entomaspididae & Heterocaryonidae & Harpididae & Harpetidae \\
\hline Entomaspididae & - & 5.195 & 5.877 & 4.383 \\
\hline Heterocaryonidae & 0.0006 & - & 12.66 & 10.42 \\
\hline Harpididae & 0.0054 & 0.0006 & - & 7.76 \\
\hline Harpetidae & 0.0006 & 0.0006 & 0.0006 & - \\
\hline
\end{tabular}

Table 4: PERMANOVA test results of Harpetida (Permutation N: 9999, Total sum of squares: 9105, Within-group sum of squares: 7230, F: 7.521, p (same): 0.0001) for statistical differences between taxa for each of the four harpetid families groupings based on PCO analyses. Values in regular font are for the Bonferroni corrected $p$-values, those in italics are the raw $\mathrm{F}$ values.

\begin{tabular}{|l|l|l|l|l|l|l|}
\hline & $\begin{array}{l}\text { Tidal } \\
\text { Flats }\end{array}$ & Reefs & $\begin{array}{l}\text { Subtidal } \\
\text { Shelf }\end{array}$ & Shoals & Slope & Deep Marine \\
\hline $\begin{array}{l}\text { Tidal } \\
\text { Flats }\end{array}$ & - & 6.604 & 5.09 & $\mathbf{5 . 2 0 5}$ & 4.019 & 5.592 \\
\hline Reefs & 0.0021 & - & 4.162 & $\mathbf{3 . 4 3 4}$ & 3.837 & 5.678 \\
\hline $\begin{array}{l}\text { Subtidal } \\
\text { Shelf }\end{array}$ & 0.0042 & 0.0042 & - & 3.297 & 2.811 & 2.726 \\
\hline Shoals & $\mathbf{0 . 0 5 6 7}$ & $\mathbf{0 . 2 1 6 3}$ & 0.021 & - & 2.804 & 3.478 \\
\hline Slope & 0.0021 & 0.0147 & 0.0021 & 0.0231 & - & 3.137 \\
\hline $\begin{array}{l}\text { Deep } \\
\text { Marine }\end{array}$ & 0.0021 & 0.0021 & 0.0399 & 0.0147 & 0.0063 & - \\
\hline
\end{tabular}

Table 5: PERMANOVA test results of Harpetida (Permutation N: 9999, Total sum of squares: 9105, Within-group sum of squares: 7270, F: 3.534, p (same): 0.0001) for statistical differences between taxa for each of the six ecological groupings based on PCO analyses. Values in regular font are for the Bonferroni corrected $p$-values, those in italics are the raw F values. Nonsignificant values (indicating no significant difference between groupings) shown in bold. 

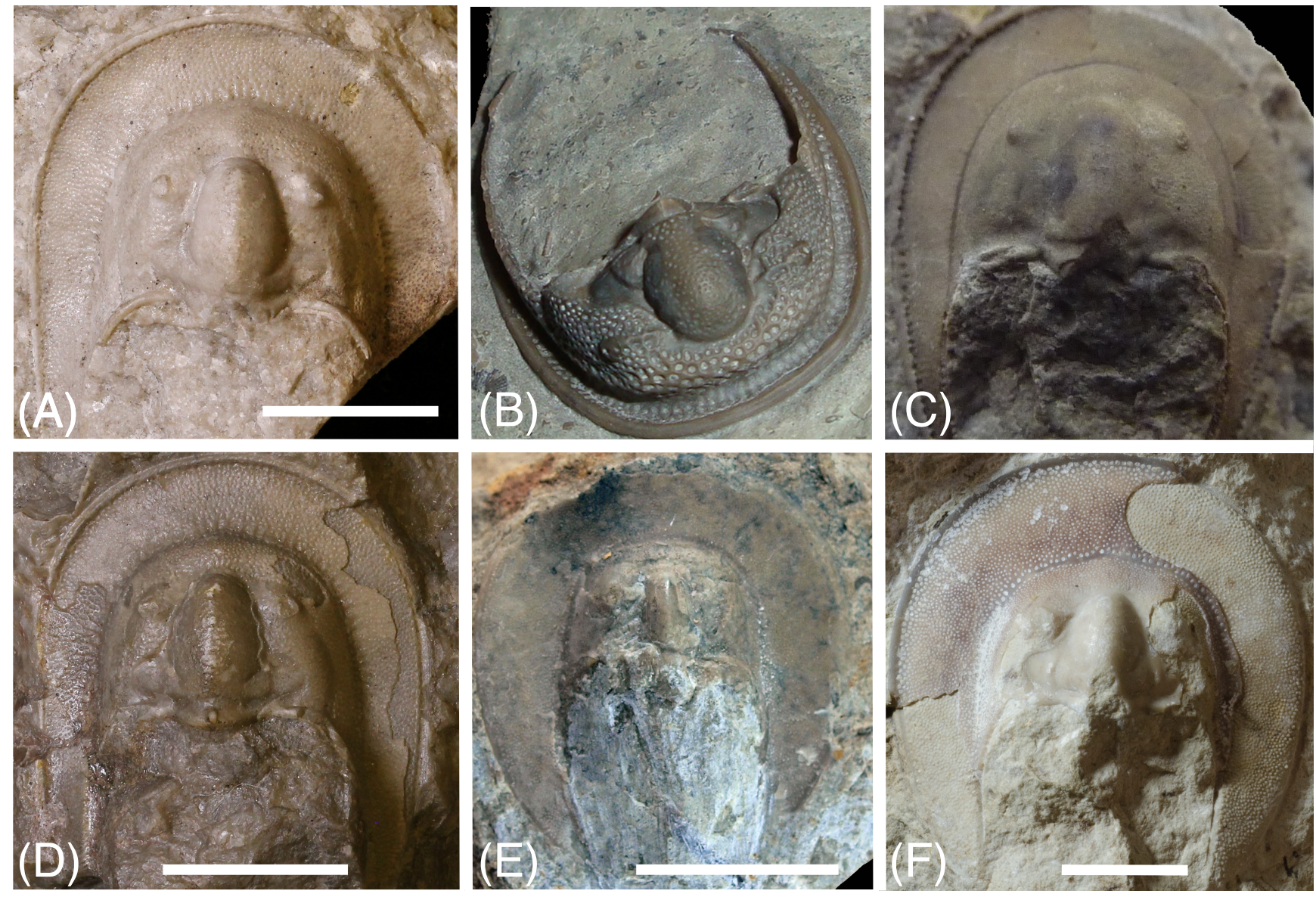

Figure 1: Fossil trilobites of the order Harpetida. A: Lioharpes venulosus , B: Dolichoharpes dentoni (?), C: Kielania dorbignyana, D: Bohemoharpes ungula, E: Scotoharpes spasskii, F: Hibbertia wegelini. $1 \mathrm{~cm}$ scale bar included where available. 


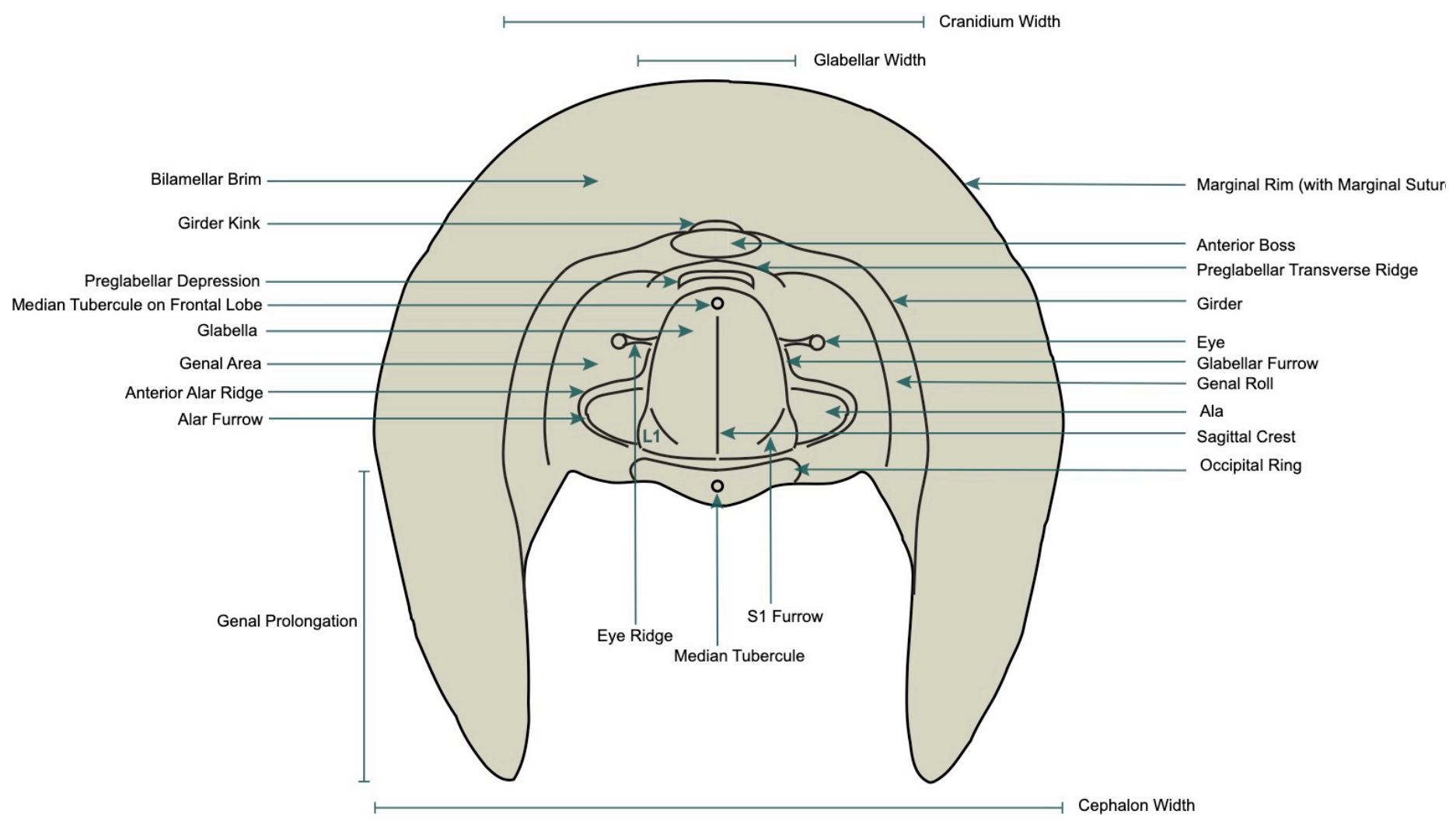

Figure 2: Morphology of the harpetid cephalon. 


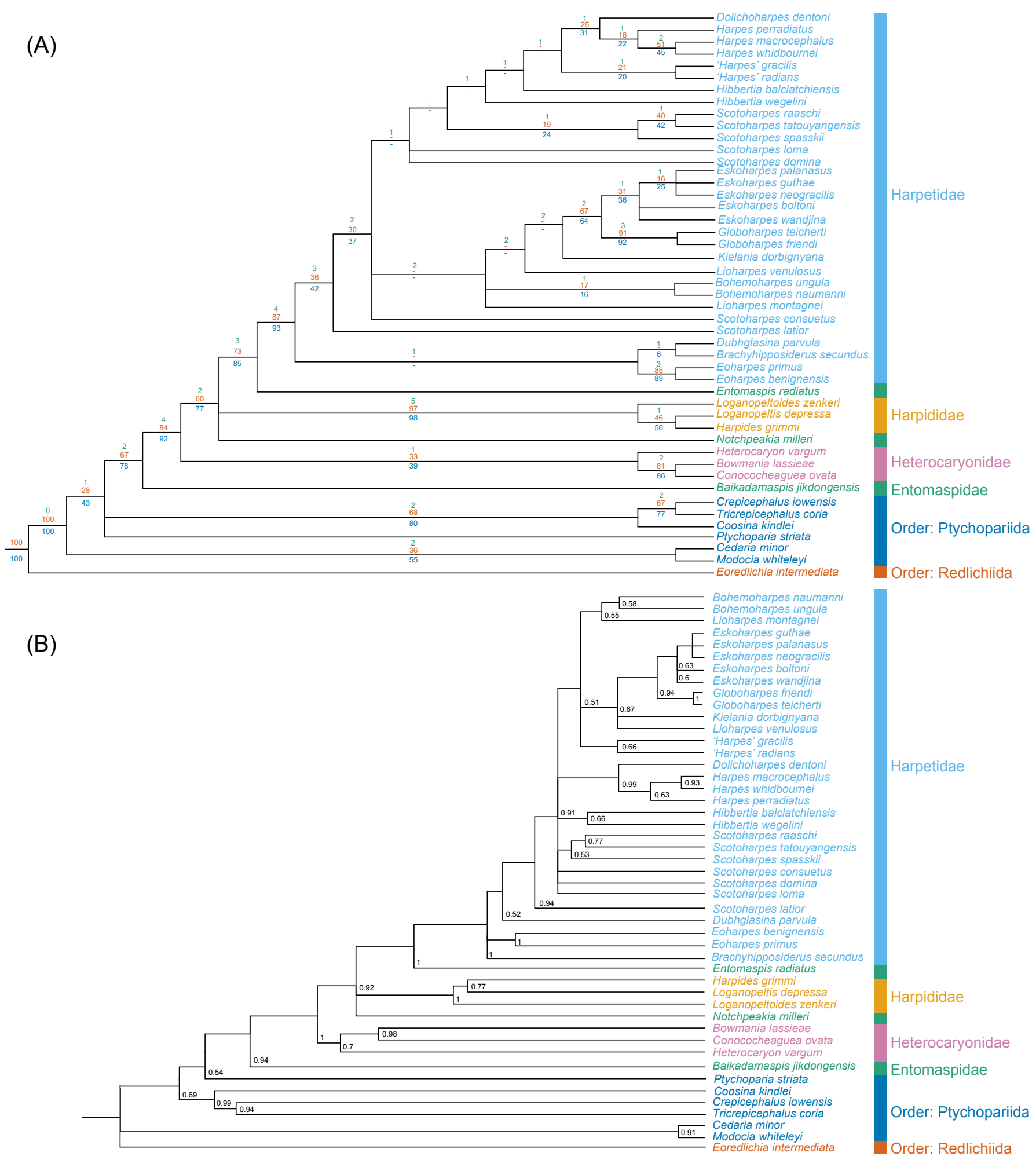

Figure 3: Revised harpetid phylogeny and harpetid families. A: Consensus of 18 most parsimonious trees from TNT. B: Bayesian tree from MrBayes. Green: Bremer support values, Red: Bootstrap values, Blue: Jackknife values, Black: posterior probabilities values. 


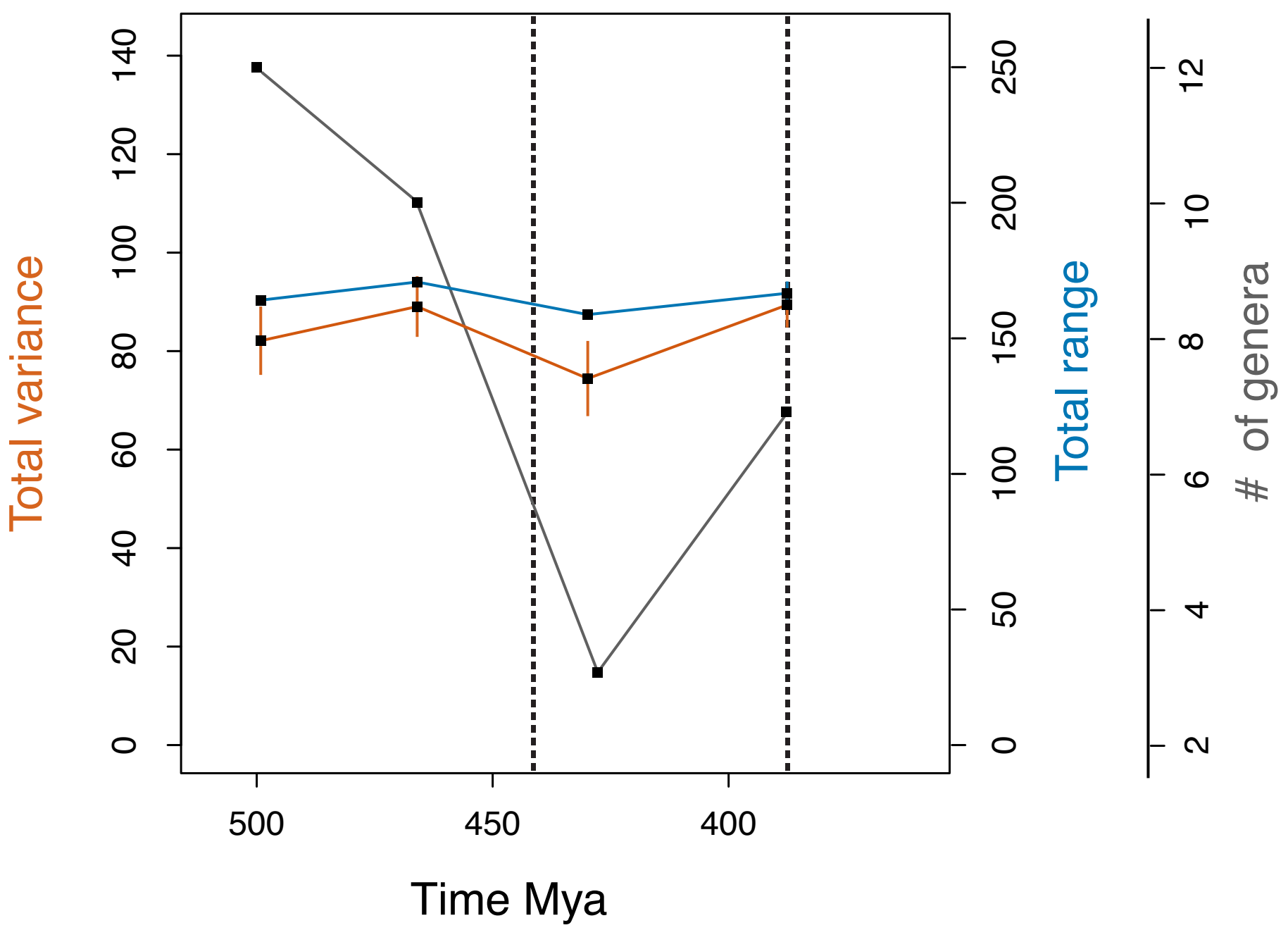

Figure 4: The disparity of the order Harpetida (sampled taxa only) through time, with period level temporal resolution. Red: Sum of variances. Blue: Sum of ranges. Minimum number of harpetid genera in relevant time bin. Dashed lines represent major mass extinction events. 

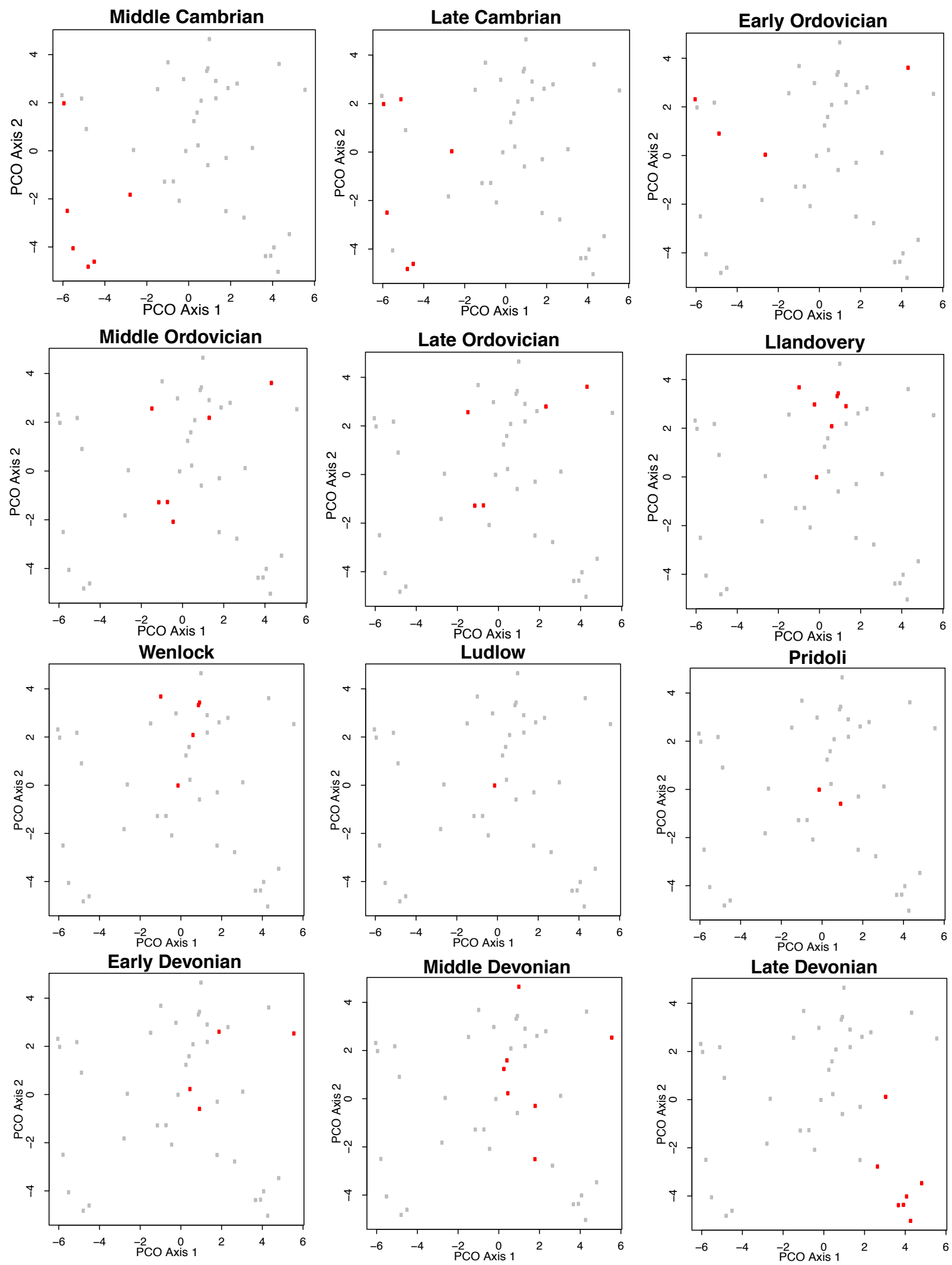

Figure 5: Harpetid morphospace (sampled taxa only) occupation through time, with epoch-level resolution. 


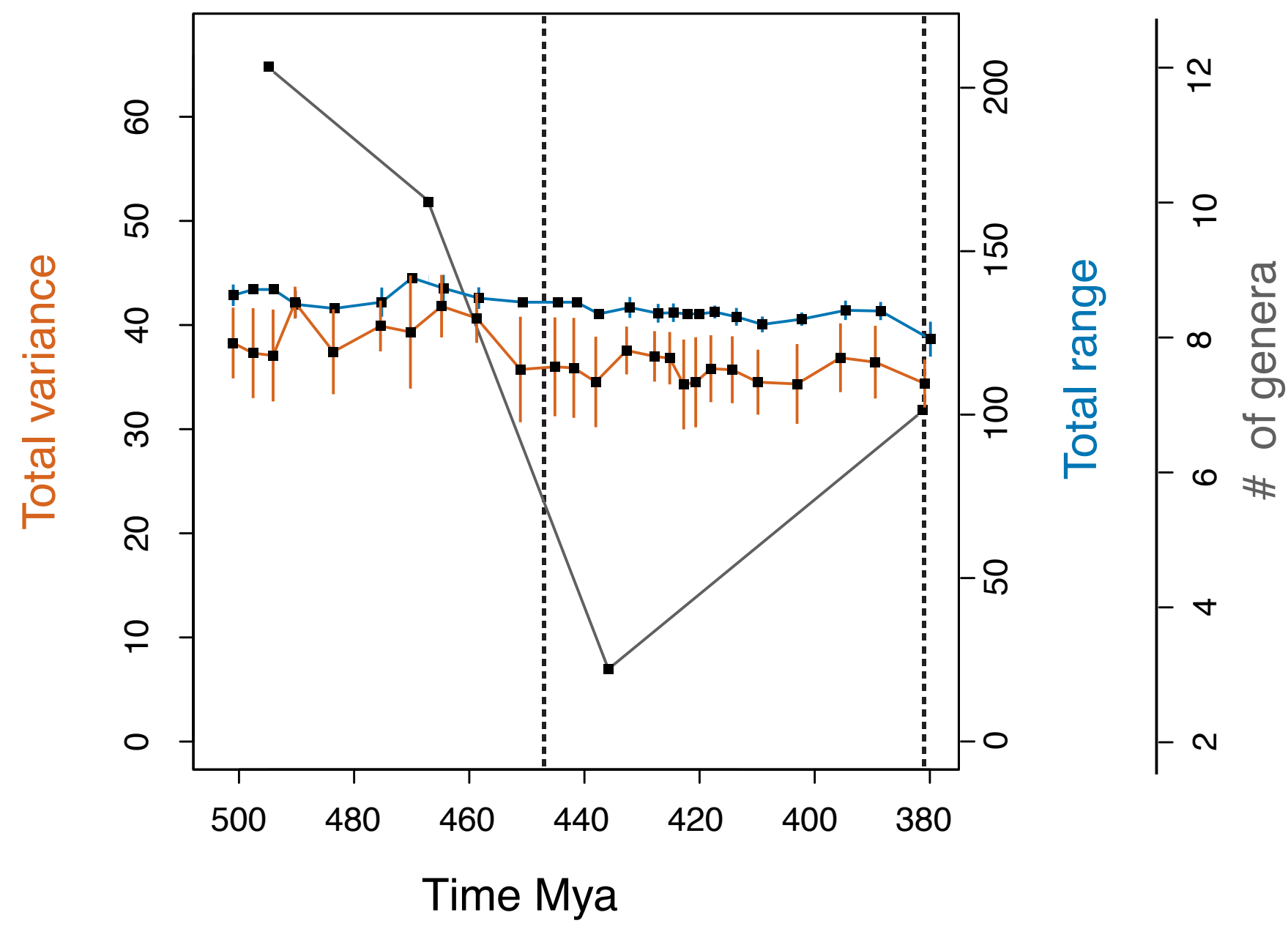

Figure 6: The disparity of the order Harpetida (including reconstructed ancestors) through time, with stage level temporal resolution. Red: Sum of variances. Blue: Sum of ranges. Minimum number of harpetid genera in relevant time bin. Dashed lines represent major mass extinction events 


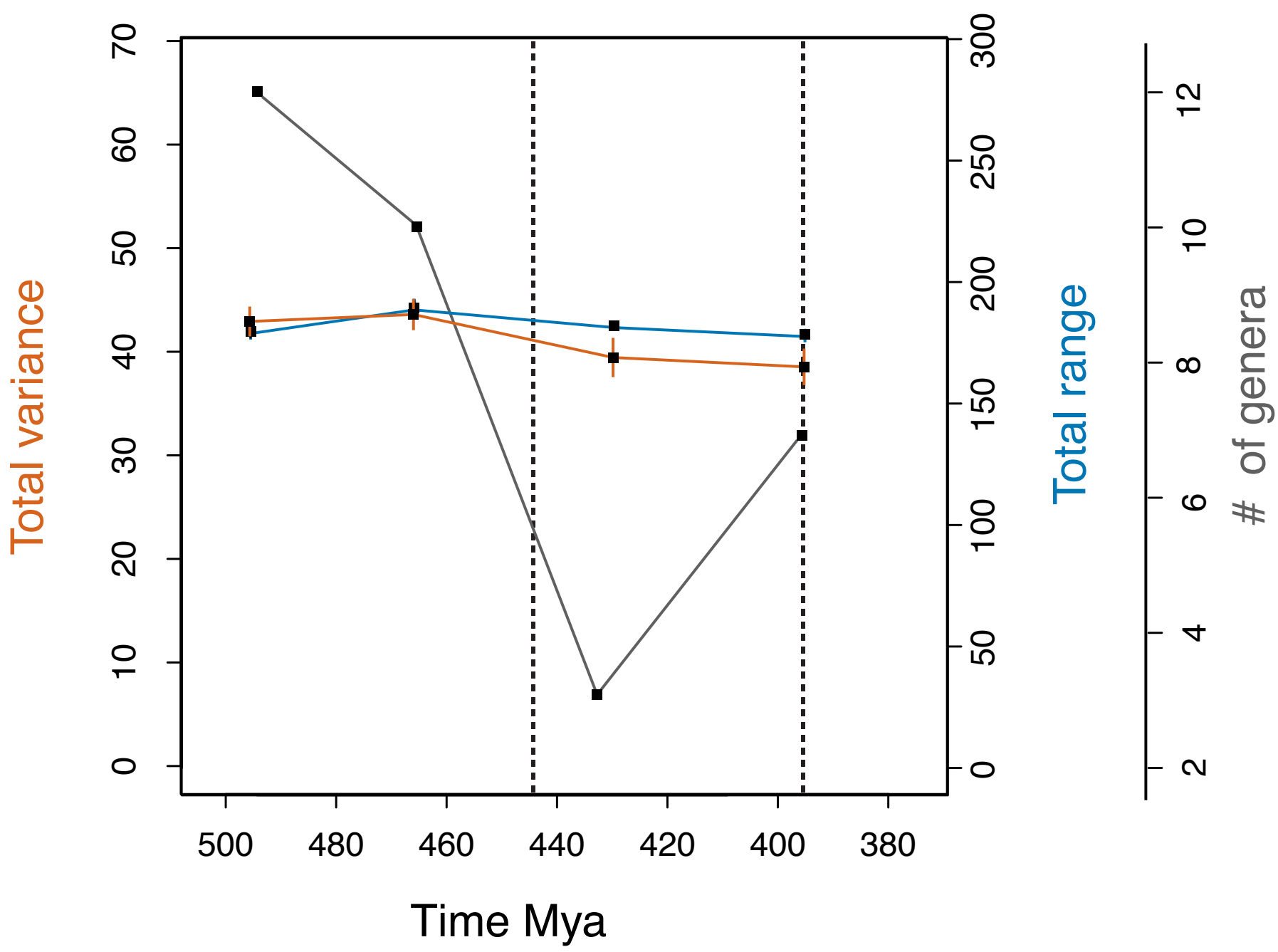

Figure 7: The disparity of the order Harpetida (including reconstructed ancestors) through time, with period level temporal resolution. Red: Sum of variances. Blue: Sum of ranges. Minimum number of harpetid genera in relevant time bin. Dashed lines represent major mass extinction events 

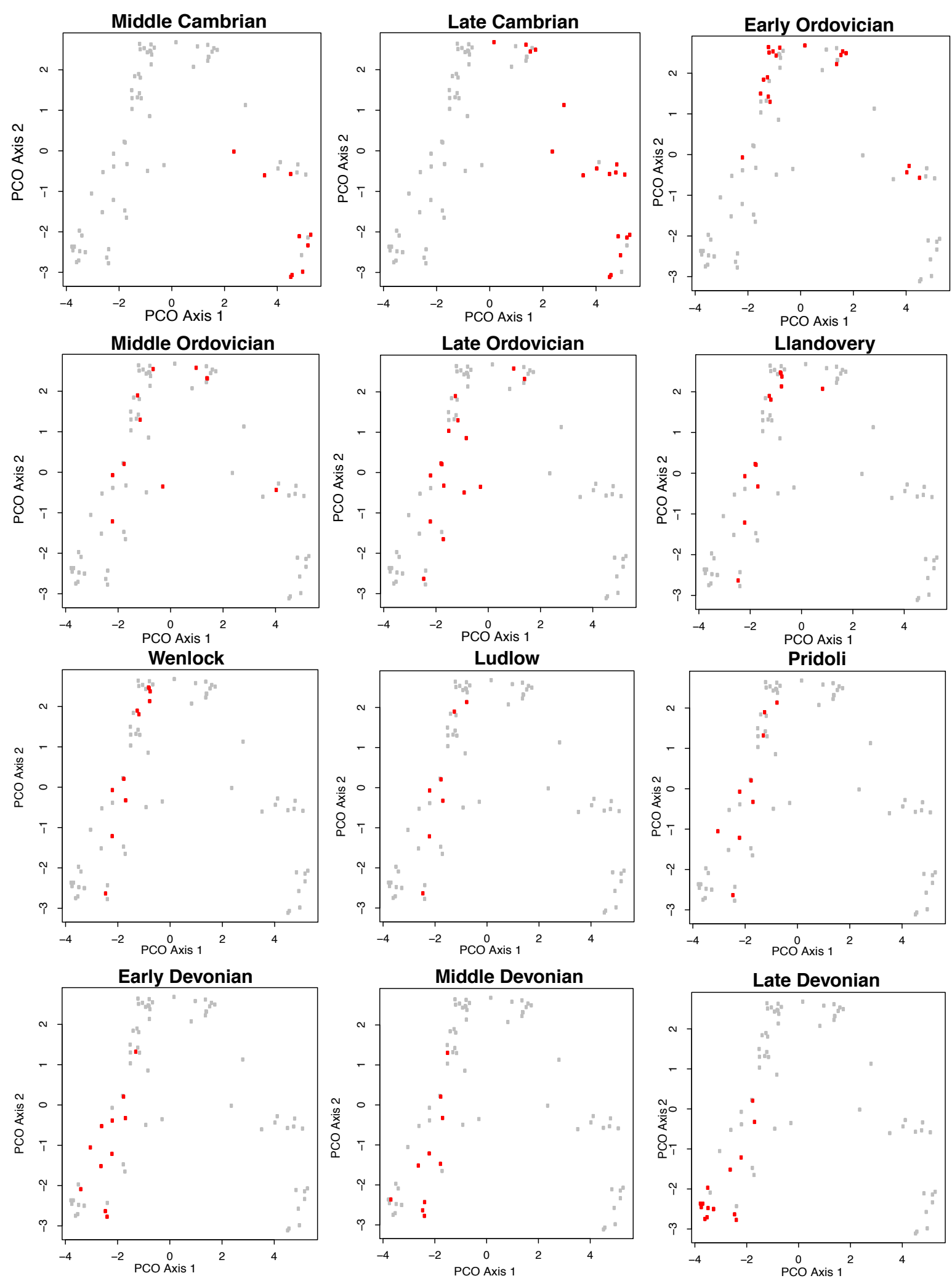

Figure 8: Phylogenetically corrected harpetid morphospace (including reconstructed ancestors) occupation through time, with epoch level resolution. 


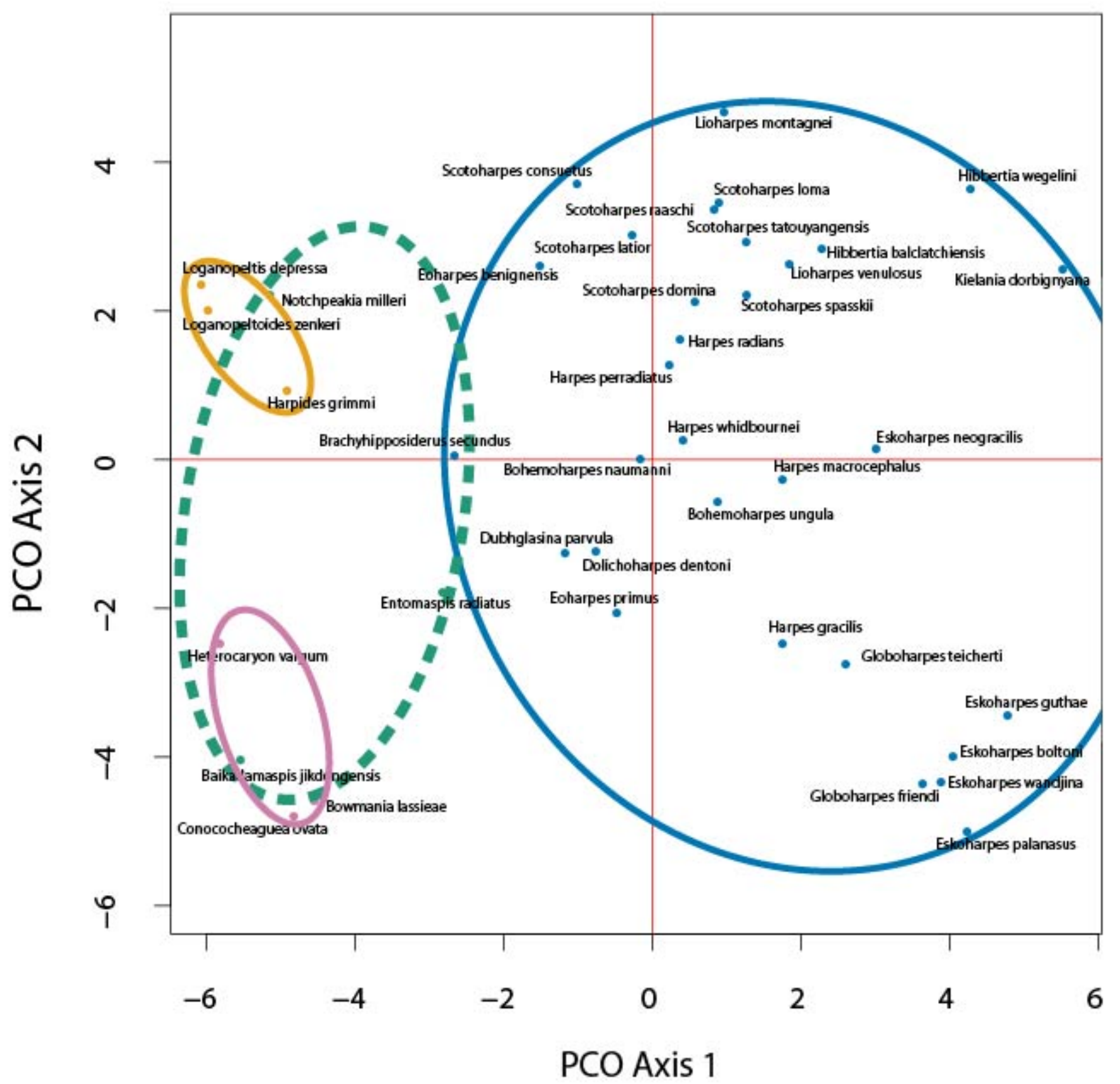

Figure 9: Harpetid morphospace, partitioned by family. Yellow: Harpididae, Green: 'Entomaspididae', Pink: Heterocaryonidae, Blue: Harpetidae. Dashed lines denote polyphyletic or paraphyletic groups. 


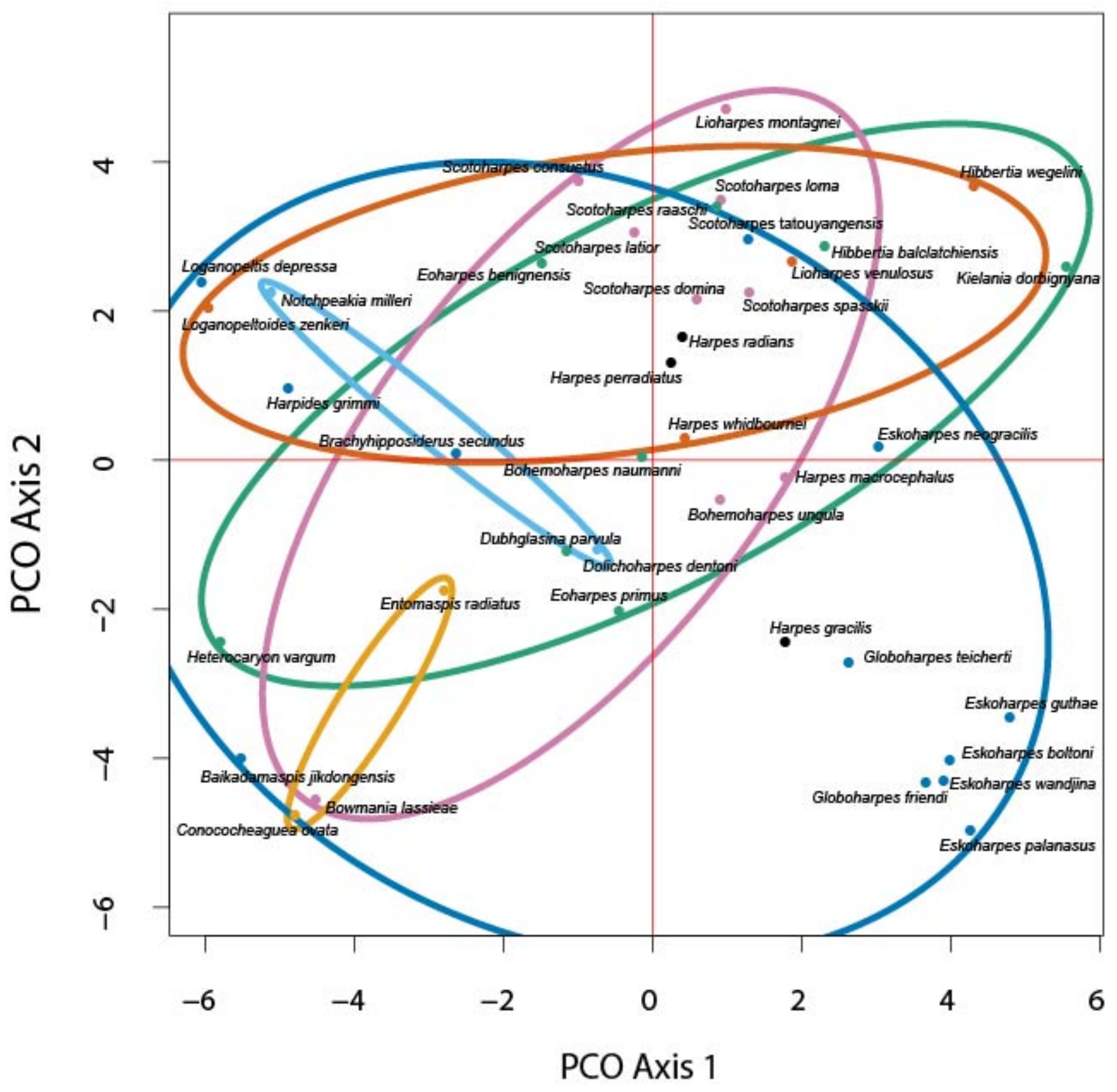

Figure 10: Harpetid morphospace, partitioned by environmental association. Yellow: tidal flats, Red: reefs, Pink: subtidal shelf, Light Blue: shoals, Dark Blue: slope, Green: deep marine, Black: unavailable. 


\section{APPENDIX 1: CHARACTER LIST}

Character 1. Angle of Cephalic Curvature greater than 90 degrees (0); 90 degrees or less (1).

Character 2. Cephalon Convexity low (0); high (1).

Character 3. Widest point of cephalon Posterior third (0); Anterior third (1).

Character 4. Marginal rim demarcated along its inner margin by enlarge pits inner margin of rim not demarcated by enlarged pits ( 0 ); row of enlarged pits demarcates inner margin of rim (1).

Character 5. Bilamellar Brim absent (0); present (1).

Character 6. Bilamellar Brim Concavity flat (0); concave (1); convex (2).

Character 7. Brim Width narrower than glabellar length (0); equal to or wider than glabellar length (1).

Character 8. Commencement of narrowing of brim along prolongations distally, brim constant in width for the majority of prolongation (0); proximally, brim narrowing almost from the level of the occipital ring (1).

Character 9. Pitting present on outer field of cephalon (including brim) absent (0); present (1).

Character 10. Brim Pitting Extent $<50 \%$ of the brim surface visibly pitted $(0) ;>50 \%$ of the brim surface visibly pitted (1).

Character 11. Pronounced radiating ridges at the genal roll/brim boundary absent (0); present (1).

Character 12. Girder Separating Genal Rolls from Brim absent (0); present (1).

Character 13. Girder Kink absent (0); present (1).

Character 14. Outer margin of genal roll demarcated by deep pits outer margin of genal roll not lined by deep pits (0); row of deep pits demarcate outer margin of genal roll (1).

Character 15. Position of Hypostome Constriction anterior quarter (0); midpoint (1).

Character 16. Median Tubercule on Frontal Lobe absent (0); present (1).

Character 17. Preglabellar Transverse Ridge absent (0); present (1).

Character 18. Anterior Preglabellar Depression absent (0); present (1).

Character 19. Anterior Boss absent (0); present (1).

Character 20. Anterior Boss Inflation slight inflation (0); bulbous (1).

Character 21. Vaulted Inner Genal Roll absent (0); present (1).

Character 22. Genal Roll Convexity convex (0); concave (1).

Character 23. Glabellar morphology narrowing anteriorly (0); widening anteriorly (1).

Character 24. Depth of S1 furrow deep, well defined (0); shallow, poorly defined (1).

Character 25. Morphology of 1st Pair of Lateral Glabellar Furrows (S1) posterolaterally directed furrows (0); J-shaped furrows not continuous with S0 (1).

Character 26. 2nd Pair of Lateral Glabellar Furrows (S2) absent (0); present (1).

Character 27. 3rd Pair of Lateral Glabellar Furrows (S3) absent (0); present (1).

Character 28. Length of 1 st Lateral Glabellar Furrows (S1) shorter than $50 \%$ of glabellar width (0); longer than $50 \%$ of glabellar width (1).

Character 29. Length of S2/S3 $\sim 50 \%$ of glabella width (0); short, $\sim 25 \%$ of glabella width (1).

Character 30. Positioning of S2 \& S3 well spaced (0); S2 \& S3 close together, L3 expanded (1).

Character 31. Cross-sectional morphology of glabellar furrows rounded (0); incised (1). 
Character 32. Curvature of Glabellar Furrows S2-S3 straight (0); incurving (curve posteriorly) (1); outcurving (curve anteriorly) (2).

Character 33. Glabellar lateral margins converging anteriorly (0); equilateral (1).

Character 34. Size of L1 L1 $<10 \%$ of glabellar volume (0); L1 $>10 \%$ of glabellar volume (1).

Character 35. Glabellar and Genal Primary Surface Ornament/Scultpure tuberculate (0); reticulation of pits (1); fine granulations (2).

Character 36. Sagittal Crest absent (0); present (1).

Character 37. Yoked Librigenae absent (0); present (1).

Character 38. Posterior Suture Position cuts through outer margin (0); skirts margin (1).

Character 39. Anterior Suture Angle From Compound Eye 30-45 degrees (0); $>$ or $=60$ degrees $(1) ;<$ or $=0$ degrees (2).

Character 40. Cephalic sutures with marked inward curve just prior to cephalic margin absent (0); present (1).

Character 41. Eye Structure eye lobes (0); tubercles (1).

Character 42. Eye Angle diverging posteriorly (0); equilateral (1).

Character 43. Lateral position of eye closer to alar furrow (0); closer to axial furrow (1).

Character 44. Anterior-posterior position of eye posterior of cephalon (0-45\%) (0); midline or anterior $\left(48 \%^{+}\right)(1)$; eye encompasses entire cephalon length (2).

Character 45 . Genal ridge running postero-laterally from eye Genal ridge absent (0); Genal ridge present (1).

Character 46. Eye Size (as percentage of cephalon) $20-30 \%(0) ;<15 \%$ (1).

Character 47. Eye Ridges absent (0); present (1).

Character 48. Eye Ridge Direction anterolaterally directed (0); posterolaterally directed (1); transversely directed (no V) (2).

Character 49. Ridge Insertion on Compound Eye anterior of eye (0); mid-point of eye (1).

Character 50. Genae Concavity flattened/moderately convex (0); concave (1); extremely convex (2).

Character 51. Radiating, Anastomosing Genal Caeca absent (0); present (1).

Character 52. Axial Furrow Depth shallow (0); deep (1).

Character 53. Extension of axial furrows beyond glabella onto genal roll absent (0); present (1).

Character 54. Alae absent (0); present (1).

Character 55. Alae strength as defined by alar furrow faint (shallow alar furrow) (0); strong (deep alar furrow) (1).

Character 56. Alae morphology subdivided into two crescentic portions by presence of interalar furrow (0); continuous, interalar furrow absent (1).

Character 57. Relief of Alae depressed or sunken (0); flattened/low relief (1); inflated (2).

Character 58. Extreme vaulting of inflated alae Inflated alae not exhibiting vaulting (0); Inflated alae vaulted (1).

Character 59. Alae Size small (smaller than L1) (0); large (equal to or larger than L1) (1).

Character 60. Alar Direction transversely/laterally directed (0); anterolaterally directed (1).

Character 61. Large pits on genal area opposite alae pits on genal area opposite alae absent or not enlarged (0); enlarged pits on genal area opposite alae (1). 
Character 62. Anterior Alar Ridge absent (0); present (1).

Character 63. Median Tubercule on Occipital Ring absent (0); present (1).

Character 64. Genal spines/prolongations Postero-lateral margin of cephalon extending into genal spines or prolongations (0); Cephalon not extending into genal spines/prolongations (1).

Character 65. Cross-sectional morphology of genal spines broad, flattened (prolongations) (0); narrow, rounded (spines) (1).

Character 66. Genal spine/prolongation curvature Interior/proximal margin straight (0); Interior/proximal margin incurving (1).

Character 67. Genal Spine Angle of Divergence high ( $>$ or $=30$ degrees) (0); moderate (11 to 29 degrees) (1); reduced ( $<$ or $=$ to 10 degrees) $(2)$.

Character 68. Curvature of genal prolongations straight (rapidly flattens from cephalon) (0); concave (twisted along length of prolongation) (1).

Character 69. Genal Spine/Prolongation Length longer than cranidium (0); equal to or shorter than cranidium length (1).

Character 70. Thoracic Axis Width narrower at broadest point than glabellar width (0); equal in width at broadest point to glabellar width (1); broader at broadest point than glabellar width (2).

Character 71. Free Thoracic Tergite Count Less than or equal to $15(0)$; More than or equal to $16(1)$.

Character 72. Form of pleural spine terminations on thoracic tergites acute, spinous (0); blunt (1).

Character 73. Pygidium With Medial Posterior Indentation absent (0); present (1).

Character 74. Number of axial rings in pygidium $4-5(0) ; 3$ (1); 2 (2); 7-8 (3).

Character 75. Pleural Field Margin downturned (0); upturned (1); flat (2).

Character 76. Terminal lappets absent (0); present (1). 


\section{APPENDIX 2: CHARACTER MATRIX}

\begin{tabular}{|c|c|c|c|c|c|c|c|c|c|c|c|c|c|c|c|c|c|c|c|c|c|c|c|c|c|c|c|c|c|c|c|c|c|c|c|c|c|c|c|}
\hline Character/taxon & 1 & 2 & 3 & 4 & 5 & 6 & 7 & 8 & 9 & 10 & 11 & 12 & 13 & 14 & 15 & 16 & 17 & 18 & 19 & 20 & 21 & 22 & 23 & 24 & 25 & 26 & 27 & 28 & 29 & 30 & 31 & 32 & 33 & 34 & 35 & 36 & 37 & 38 & 39 \\
\hline E. intermedia & 0 & 0 & 0 & 0 & 0 & - & - & - & 0 & - & - & 0 & - & - & 0 & 0 & 0 & 0 & 0 & - & - & - & 0 & 0 & 0 & 1 & 1 & 1 & 0 & 0 & 1 & 2 & 0 & 1 & 2 & 0 & 0 & 0 & 0 \\
\hline B. jikdongensis & 0 & 0 & 0 & 0 & 0 & - & - & - & 0 & - & - & 0 & - & - & ? & 0 & 0 & 0 & 0 & - & - & - & 0 & 0 & 0 & 1 & 1 & 0 & 1 & 0 & 1 & 2 & 0 & 1 & 0 & 0 & 0 & 0 & 1 \\
\hline B. naumanni & 1 & 1 & 0 & 1 & 1 & 0 & 1 & 0 & 1 & 1 & 1 & 1 & 0 & 1 & $?$ & 0 & 0 & 0 & 1 & 0 & 0 & 2 & 0 & 0 & 1 & 0 & 0 & 0 & - & - & 1 & - & 0 & 0 & 1 & 0 & 1 & 1 & - \\
\hline B. ungula & 1 & 1 & 0 & 1 & 1 & 0 & 0 & 0 & 1 & 1 & 1 & 1 & 1 & 1 & ? & 1 & 0 & 0 & 1 & 0 & 0 & 2 & 0 & 0 & 1 & 0 & 0 & 0 & - & - & 1 & - & 0 & 0 & 1 & 0 & 1 & 1 & - \\
\hline B. lassieae & 0 & 1 & 0 & 0 & 0 & - & - & - & 0 & - & - & 0 & - & - & 1 & 0 & 0 & 0 & 0 & - & - & - & 1 & 0 & 0 & 1 & 1 & 0 & 1 & 0 & 1 & 2 & 1 & 0 & 0 & 0 & 1 & 0 & 1 \\
\hline B. secundus & 1 & 1 & 0 & 0 & 1 & 0 & 1 & 0 & 1 & 1 & 0 & 1 & 0 & 0 & $?$ & 0 & 0 & 0 & 0 & - & 0 & 2 & 0 & 0 & 0 & 1 & 0 & 0 & 1 & - & 1 & 0 & 0 & 0 & 1 & 0 & 1 & 1 & - \\
\hline C. ovata & 0 & 1 & 0 & 0 & 0 & - & - & - & 0 & - & - & 0 & - & - & $?$ & 0 & 0 & 0 & 0 & - & - & - & 1 & 0 & 0 & 1 & 1 & 0 & 1 & 0 & 1 & 2 & 1 & 0 & 0 & 0 & ? & 0 & 1 \\
\hline D. dentoni & 1 & 1 & 0 & 1 & 1 & 1 & 0 & 1 & 1 & 1 & 0 & 1 & 0 & 1 & $?$ & 0 & 0 & 0 & 0 & - & 0 & 2 & 0 & 0 & 0 & 1 & 0 & 0 & 1 & 0 & 1 & 1 & 0 & 0 & 1 & 0 & 1 & 1 & - \\
\hline D. parvula & 1 & 1 & 0 & 0 & 1 & 0 & 1 & 0 & 1 & 0 & 0 & 1 & 0 & 0 & $?$ & 0 & 0 & 0 & 0 & - & 0 & 2 & 0 & 0 & 0 & 0 & 0 & 0 & - & - & 1 & - & 0 & 0 & 1 & 0 & 1 & 1 & - \\
\hline E. radiatus & 1 & 1 & 0 & 0 & 1 & 2 & 0 & - & 1 & 1 & 1 & 1 & 0 & 0 & 1 & 0 & 0 & 0 & 0 & - & 0 & 2 & 0 & 0 & 0 & 1 & 0 & 0 & 1 & 0 & 1 & 0 & 0 & 0 & 0 & 0 & 1 & 0 & 1 \\
\hline E. benignensis & 1 & 1 & 0 & 0 & 1 & 0 & 0 & 0 & 1 & 1 & 0 & 1 & 0 & 0 & ? & 0 & 0 & 1 & 0 & - & 0 & 1 & 0 & 0 & 0 & 1 & 0 & 0 & 1 & - & 1 & 0 & 0 & 0 & 1 & 0 & 1 & 1 & - \\
\hline E.primus & 1 & 1 & 0 & 0 & 1 & 0 & 0 & 0 & 1 & 1 & 0 & 1 & 0 & 0 & $?$ & 0 & 0 & 1 & 0 & - & 0 & 1 & 0 & 0 & 0 & 1 & 0 & 0 & 1 & - & 1 & 0 & 0 & 0 & 1 & 0 & 1 & 1 & - \\
\hline E. boltoni & 1 & 1 & 1 & 1 & 1 & 1 & 0 & 1 & 1 & 1 & 0 & 1 & 1 & 1 & $?$ & 0 & 0 & 0 & 1 & 0 & 0 & 2 & 0 & 1 & 0 & 0 & 0 & 1 & - & - & 1 & - & 0 & 0 & 0 & 1 & 1 & 1 & - \\
\hline E. guthae & 1 & 1 & 1 & 1 & 1 & 2 & 0 & 1 & 1 & 1 & 0 & 1 & 1 & 1 & ? & 0 & 0 & 0 & 1 & 0 & 0 & 2 & 0 & 1 & $?$ & 0 & 0 & 1 & - & - & ? & - & 0 & $?$ & 0 & 1 & 1 & 1 & - \\
\hline E. palanasus & 1 & 1 & 1 & 1 & 1 & 2 & 0 & 1 & 1 & 1 & 0 & 1 & 1 & 1 & 1 & 0 & 0 & 0 & 1 & 0 & 0 & 2 & 0 & 1 & 0 & 0 & 0 & 1 & - & - & 1 & - & 0 & 0 & 0 & 1 & 1 & 1 & - \\
\hline E. wandjina & 1 & 1 & 1 & 1 & 1 & 1 & 0 & 1 & 1 & 1 & 0 & 1 & 1 & 1 & $?$ & 0 & 0 & 0 & 1 & 0 & 0 & 2 & 0 & 1 & 0 & 0 & 0 & 1 & - & - & 1 & - & 0 & 0 & 0 & 1 & 1 & 1 & - \\
\hline G. friendi & 1 & 1 & 1 & 1 & 1 & 2 & 0 & 1 & 1 & 1 & 0 & 1 & 1 & 1 & $?$ & 0 & 0 & 0 & 1 & 1 & 1 & 2 & 0 & 0 & 0 & 0 & 0 & 1 & - & - & 1 & - & 0 & 0 & 0 & 1 & 1 & 1 & - \\
\hline G. teicherti & 1 & 1 & 1 & 1 & 1 & 2 & 0 & 1 & 1 & 1 & 0 & 1 & 1 & 1 & $?$ & 0 & 0 & 0 & 1 & 1 & 1 & 2 & 0 & 0 & 0 & 0 & 0 & 1 & - & - & 1 & - & 0 & 0 & 0 & 1 & 1 & 1 & - \\
\hline H. gracilis & 1 & 1 & $?$ & ? & 1 & 0 & 0 & ? & 1 & 1 & 0 & 1 & ? & 1 & $?$ & 0 & 0 & 0 & 1 & 0 & 0 & 2 & $?$ & 0 & 0 & $?$ & $?$ & $?$ & $?$ & $?$ & 1 & $?$ & 0 & 0 & 0 & 1 & 1 & 1 & - \\
\hline H.macrocephalus & 1 & 1 & 1 & 1 & 1 & 1 & 0 & 1 & 1 & 1 & 0 & 1 & 1 & 1 & 1 & 0 & 1 & 0 & 1 & 0 & 0 & 2 & 0 & 0 & 0 & 0 & 0 & 1 & - & - & 1 & - & 0 & 0 & 0 & 0 & 1 & 1 & - \\
\hline 'H.' neogracilis & 1 & 1 & 1 & 1 & 1 & 2 & 0 & 1 & 1 & 1 & 0 & 1 & 1 & 1 & ? & 0 & 0 & 0 & 1 & 0 & 0 & 2 & 0 & 1 & ? & 0 & 0 & 1 & - & - & ? & - & 0 & ? & 0 & 1 & 1 & 1 & - \\
\hline H. whidbournei & 1 & 1 & 1 & 1 & 1 & 1 & 0 & 1 & 1 & 1 & 0 & 1 & 1 & 1 & $?$ & 0 & $?$ & 0 & 1 & 0 & 0 & 2 & 0 & 0 & 0 & 0 & 0 & 1 & - & - & 1 & - & 0 & 1 & $?$ & 0 & 1 & 1 & - \\
\hline H. grimmi & ? & 0 & 0 & 0 & 0 & - & - & - & 1 & 1 & - & 0 & - & - & 1 & 0 & 0 & 0 & 0 & - & - & - & ? & 0 & 0 & 1 & 1 & 0 & 1 & 1 & 1 & 2 & 0 & 0 & 1 & 0 & 1 & 1 & - \\
\hline H. perradiatus & 1 & 1 & 1 & 1 & 1 & 1 & 0 & 1 & 1 & 1 & 0 & 1 & 1 & 1 & $?$ & 0 & 0 & 0 & 0 & - & 0 & 2 & 0 & 0 & 0 & 0 & 0 & 1 & - & - & 1 & - & 0 & 0 & 1 & 0 & 1 & 1 & - \\
\hline H. radians & 1 & 1 & 0 & 1 & 1 & 0 & 0 & 0 & 1 & 1 & 0 & 1 & 0 & 1 & $?$ & 0 & 0 & 0 & 1 & - & 0 & 2 & 0 & 0 & 0 & 0 & 0 & 0 & - & - & 1 & - & 0 & 0 & 1 & 1 & 1 & 1 & - \\
\hline H. vargum & 0 & 1 & 0 & 0 & 0 & - & - & - & 0 & - & - & 0 & - & - & $?$ & $?$ & 0 & 0 & 0 & - & - & - & 0 & 0 & 0 & 1 & 1 & 0 & 1 & 0 & 1 & 0 & 1 & 0 & 0 & 0 & 1 & 0 & 2 \\
\hline H.balclatchiensis & 1 & 1 & 0 & 1 & 1 & 0 & 0 & 0 & 1 & 1 & 0 & 1 & 0 & 1 & $?$ & 0 & 0 & 0 & 0 & - & 0 & 2 & 0 & ? & $?$ & 0 & 0 & $?$ & - & - & ? & $?$ & 0 & $?$ & 1 & 0 & 1 & 1 & - \\
\hline H. wegelini & 1 & 1 & 0 & 1 & 1 & 2 & 0 & 0 & 1 & 1 & 0 & 1 & 1 & 1 & ? & 0 & 1 & 0 & 0 & - & 0 & 2 & 0 & 0 & 0 & 0 & 0 & 1 & - & - & 1 & - & 0 & 1 & 1 & 0 & 1 & 1 & - \\
\hline K. dorbignyana & 1 & 1 & 1 & 1 & 1 & 1 & 0 & 1 & 1 & 1 & 0 & 1 & 1 & $?$ & $?$ & 0 & 0 & 0 & 1 & 0 & 0 & 2 & 0 & 0 & 0 & 0 & 0 & 0 & - & - & 1 & - & 0 & 0 & $?$ & 0 & 1 & 1 & - \\
\hline L. montagnei & 1 & 1 & 0 & 1 & 1 & 2 & 0 & 0 & 1 & 1 & 1 & 1 & 1 & 1 & ? & 0 & 1 & 0 & 1 & 0 & 0 & 2 & 0 & ? & ? & 0 & 0 & 0 & - & - & ? & - & 0 & $?$ & 1 & 0 & 1 & 1 & - \\
\hline L. venulosus & 1 & 1 & 1 & 1 & 1 & 1 & 0 & 1 & 1 & 1 & 1 & 1 & 1 & 1 & $?$ & 1 & 1 & 0 & 1 & 0 & 0 & 2 & 0 & 0 & 0 & 0 & 0 & 0 & - & - & 1 & - & 0 & 0 & 0 & 1 & 1 & 1 & - \\
\hline L. depressa & 0 & 0 & 0 & 0 & 0 & - & - & - & 1 & 1 & - & 0 & - & - & $?$ & 0 & 0 & 0 & 0 & - & - & - & 0 & 0 & 0 & 1 & 1 & 0 & 1 & 1 & 1 & 0 & 0 & 0 & 1 & 0 & 1 & 1 & - \\
\hline L. zenkeri & 0 & 0 & 0 & 0 & 0 & - & - & - & 1 & 1 & - & 0 & - & - & ? & 0 & 0 & 0 & 0 & - & - & - & 0 & 0 & 0 & 1 & 1 & 0 & 1 & 1 & 1 & 0 & 0 & 0 & 1 & 0 & 1 & 0 & 1 \\
\hline N. milleri & 0 & 0 & 0 & 1 & 0 & - & - & - & 1 & 1 & - & 0 & - & - & 1 & 0 & 0 & 0 & 0 & - & - & - & 0 & 0 & 0 & 1 & 0 & 0 & 1 & - & 1 & 0 & 0 & 0 & 1 & 0 & 1 & 0 & 2 \\
\hline S. consuetus & 1 & 1 & 0 & 1 & 1 & 0 & 0 & 0 & 1 & 1 & 0 & 1 & 1 & 1 & ? & 0 & 0 & 0 & 0 & - & 0 & 2 & 0 & 0 & 0 & 0 & 0 & 0 & - & - & 1 & - & 0 & 0 & $?$ & 0 & 1 & 1 & - \\
\hline S. domina & 1 & 1 & 0 & $?$ & 1 & 0 & 0 & 0 & 1 & 1 & 0 & 1 & 1 & $?$ & $?$ & 0 & 1 & 0 & 0 & - & 0 & 2 & 0 & 0 & 0 & 0 & 0 & 0 & - & - & 1 & - & 0 & 0 & $?$ & 0 & 1 & 1 & - \\
\hline S. latior & ? & 1 & 0 & 0 & 1 & 0 & $?$ & 0 & 1 & 1 & 1 & 1 & 1 & 0 & ? & 0 & 0 & 0 & 0 & - & 0 & 2 & 0 & 0 & 0 & 0 & 0 & 0 & - & - & 1 & - & 0 & 0 & $?$ & 0 & 1 & 1 & - \\
\hline S. loma & 1 & 1 & 0 & 1 & 1 & 0 & 0 & 0 & 1 & 1 & 1 & 1 & 1 & 1 & ? & 0 & 0 & 0 & 0 & - & 0 & 2 & 0 & 0 & 0 & 0 & 0 & 0 & - & - & 1 & - & 0 & 0 & 1 & 0 & 1 & 1 & - \\
\hline S. raaschi & 1 & 1 & 0 & 1 & 1 & 0 & 1 & 0 & 1 & 1 & 0 & 1 & 1 & 1 & $?$ & 0 & 0 & 0 & 0 & - & 0 & 2 & 0 & 0 & 0 & 0 & 0 & 0 & - & - & 1 & - & 0 & 0 & 1 & 0 & 1 & 1 & - \\
\hline S. spasskii & 1 & 1 & 0 & 1 & 1 & 0 & 1 & 0 & 1 & 1 & 0 & 1 & 0 & 1 & ? & 0 & 0 & 0 & 0 & - & 0 & 2 & 0 & 0 & 0 & 0 & 0 & 0 & - & - & 1 & - & 0 & 0 & 1 & 0 & 1 & 1 & - \\
\hline S. tatouyangensis & $?$ & 1 & $?$ & $?$ & 1 & $?$ & 1 & $?$ & 1 & 1 & 0 & 1 & 1 & 1 & $?$ & 0 & 0 & 0 & 0 & - & 0 & 2 & 0 & 0 & 0 & 0 & 0 & 0 & - & - & 1 & - & 0 & 0 & 1 & 0 & 1 & 1 & - \\
\hline C. minor & 0 & 0 & 0 & 0 & 0 & - & - & - & 0 & - & - & 0 & - & - & 0 & 0 & 0 & 0 & 0 & - & - & - & 0 & 0 & 0 & 1 & 0 & 1 & 0 & - & 1 & 0 & 0 & 1 & 2 & 0 & 0 & 0 & 0 \\
\hline C. kindlei & 0 & 0 & 0 & 0 & 0 & - & - & - & 0 & - & - & 0 & - & - & $?$ & 0 & 0 & 0 & 0 & - & - & - & 0 & 0 & 0 & 1 & 1 & 0 & 1 & 0 & 0 & 2 & 0 & 1 & 2 & 0 & 0 & 0 & 0 \\
\hline C. iowensis & 0 & 0 & 0 & 0 & 0 & - & - & - & 0 & - & - & 0 & - & - & 0 & 0 & 0 & 0 & 0 & - & - & - & 0 & 0 & 0 & 0 & 0 & 0 & - & - & 0 & - & 0 & 1 & 2 & 0 & 0 & 0 & 0 \\
\hline M. whiteleyi & 0 & 0 & 0 & 1 & 0 & - & - & - & 0 & - & - & 0 & - & - & $?$ & 0 & 0 & 0 & 0 & - & - & - & 0 & 0 & 0 & 1 & 0 & 1 & 0 & - & 1 & 0 & 0 & 1 & 2 & 0 & 0 & 0 & 0 \\
\hline P. striata & 0 & 0 & 0 & $?$ & 0 & - & - & - & 0 & - & - & 0 & - & - & $?$ & 0 & 0 & 0 & 0 & - & - & - & 0 & 0 & 0 & 1 & 1 & 1 & 1 & 0 & 1 & 2 & 0 & 1 & 2 & 0 & 0 & 0 & 2 \\
\hline T. coria & 0 & 0 & 0 & 1 & 0 & - & - & - & 0 & - & - & 0 & - & - & $?$ & 0 & 0 & 0 & 0 & - & - & - & 0 & 0 & 0 & 0 & 0 & 0 & - & - & 0 & - & 0 & 1 & 0 & 0 & 0 & 0 & 0 \\
\hline
\end{tabular}




\begin{tabular}{|c|c|c|c|c|c|c|c|c|c|c|c|c|c|c|c|c|c|c|c|c|c|c|c|c|c|c|c|c|c|c|c|c|c|c|c|c|c|}
\hline Character/taxon & 40 & 41 & 42 & 43 & 44 & 45 & 46 & 47 & 48 & 49 & 50 & 51 & 52 & 53 & 54 & 55 & 56 & 57 & 58 & 59 & 60 & 61 & 62 & 63 & 64 & 65 & 66 & 67 & 68 & 69 & 70 & 71 & 72 & 73 & 74 & 75 & 76 \\
\hline E. intermedia & 0 & 0 & 0 & - & 2 & 0 & 0 & 1 & 0 & 0 & 0 & 0 & 1 & 0 & 0 & - & - & - & - & - & - & - & - & 0 & 0 & 1 & 1 & 0 & - & 0 & 1 & 0 & 0 & 0 & 1 & 0 & 0 \\
\hline B. jikdongensis & 0 & 0 & 0 & - & 1 & 0 & 1 & 1 & 0 & 0 & 0 & 0 & 1 & 0 & 0 & - & - & - & - & - & - & - & - & 1 & 0 & 1 & 1 & 0 & - & 1 & $?$ & $?$ & 1 & 0 & 1 & 0 & 0 \\
\hline B. naumanni & - & 1 & 1 & 1 & 1 & 0 & 1 & 1 & 2 & 1 & 2 & 0 & 1 & 1 & 1 & 0 & 1 & 0 & - & 0 & 1 & 0 & 0 & 0 & 0 & 0 & 1 & 2 & 0 & 1 & 0 & $?$ & $?$ & $?$ & $?$ & $?$ & $?$ \\
\hline B. ungula & - & 1 & 1 & 1 & 1 & 0 & 1 & 0 & - & - & 2 & 0 & 1 & 1 & 1 & 0 & 1 & 0 & - & 0 & 0 & 0 & 0 & 1 & 0 & 0 & 1 & 2 & 0 & 1 & 0 & 0 & 1 & 0 & $?$ & 2 & 0 \\
\hline B. lassieae & 0 & 0 & 0 & - & 1 & 0 & 1 & 1 & 0 & 0 & 2 & 0 & 1 & 0 & 0 & - & - & - & - & - & - & - & - & 0 & 0 & 1 & 1 & 0 & - & 0 & $?$ & ? & 1 & ? & 3 & 1 & 0 \\
\hline B. secundus & - & 1 & 1 & 1 & 1 & 0 & 1 & 1 & 0 & 1 & 2 & 0 & 1 & 0 & 1 & 0 & 1 & 0 & - & 0 & 1 & 0 & $?$ & 0 & 0 & $0 \& 1$ & 1 & 2 & 0 & 1 & $?$ & $?$ & $?$ & $?$ & $?$ & $?$ & $?$ \\
\hline C. ovata & 0 & 0 & 0 & - & 1 & 0 & 1 & 1 & 0 & 0 & 2 & 0 & 1 & 0 & 0 & - & - & - & - & - & - & - & - & 1 & $?$ & $?$ & $?$ & $?$ & $?$ & $?$ & $?$ & $?$ & $?$ & 0 & 3 & 1 & 0 \\
\hline D. dentoni & - & 1 & 1 & 0 & 1 & 0 & 1 & 1 & 0 & 1 & 2 & 0 & 1 & 0 & 1 & 1 & 0 & 0 & - & 1 & 1 & 0 & 1 & 0 & 0 & 0 & 1 & 1 & 1 & 0 & 0 & 1 & 1 & 0 & 1 & 2 & 0 \\
\hline D. parvula & - & 1 & 1 & 1 & 1 & 0 & 1 & 0 & - & - & 2 & 0 & 1 & 0 & 1 & 0 & 1 & 0 & - & 0 & 1 & 0 & 0 & 0 & 0 & 0 & 1 & 2 & 0 & 1 & $?$ & $?$ & $?$ & $?$ & $?$ & $?$ & $?$ \\
\hline E. radiatus & 0 & 0 & 1 & - & 0 & 0 & 1 & 1 & 0 & 1 & 2 & 0 & 1 & 0 & 0 & - & - & - & - & - & - & - & - & 0 & 0 & 1 & 1 & 2 & - & 1 & $?$ & $?$ & ? & 0 & 0 & 1 & 0 \\
\hline E. benignensis & - & 1 & 1 & 1 & 1 & 0 & 1 & 1 & 0 & 1 & 2 & 0 & 1 & 0 & 1 & 0 & 1 & 0 & - & 1 & 1 & 0 & 0 & 0 & 0 & 0 & 1 & 2 & 0 & 1 & 1 & 0 & 1 & 0 & 1 & 2 & 0 \\
\hline E. primus & - & 1 & 1 & 1 & 1 & 0 & 1 & 1 & 0 & 1 & 2 & 0 & 1 & 0 & 1 & 0 & 1 & 0 & - & 1 & 1 & 0 & 0 & 0 & 0 & 0 & 1 & 2 & 0 & 1 & 1 & 0 & 1 & 0 & ? & 2 & 0 \\
\hline E. boltoni & - & 1 & 1 & 1 & 1 & 0 & 1 & 1 & 2 & 1 & 2 & 0 & 1 & 1 & 1 & 1 & 1 & 1 & - & 1 & 0 & 0 & 0 & 1 & 0 & 0 & 1 & 2 & 0 & 0 & $?$ & $?$ & $?$ & $?$ & $?$ & $?$ & $?$ \\
\hline E. guthae & - & 1 & 1 & 1 & 1 & 0 & 1 & 1 & 1 & 1 & 2 & 0 & 1 & 1 & 1 & 1 & 1 & 1 & - & 1 & 0 & 0 & 0 & $?$ & 0 & 0 & 1 & 2 & 0 & 0 & $?$ & $?$ & $?$ & ? & $?$ & ? & ? \\
\hline E. palanasus & - & 1 & 1 & 1 & 1 & 0 & 1 & 1 & 1 & 1 & 2 & 0 & 1 & 1 & 1 & 1 & 1 & 1 & - & 1 & 0 & 0 & 0 & 1 & 0 & 0 & 0 & 2 & 0 & 0 & 0 & $?$ & 1 & 0 & $?$ & 2 & 0 \\
\hline E. wandjina & - & 1 & 1 & 1 & 1 & 0 & 1 & 1 & 2 & 1 & 2 & 0 & 1 & 1 & 1 & 0 & 1 & 1 & - & 1 & 0 & 0 & 0 & $?$ & 0 & 0 & 1 & 2 & 0 & 0 & $?$ & $?$ & $?$ & $?$ & $?$ & $?$ & ? \\
\hline G. friendi & - & 1 & 1 & 1 & 1 & 0 & 1 & 1 & 2 & 1 & 2 & 0 & 1 & 1 & 1 & 1 & 1 & 0 & - & 1 & 0 & 0 & 0 & 1 & 0 & 0 & 0 & 2 & 0 & 0 & $?$ & ? & ? & ? & $?$ & $?$ & ? \\
\hline G. teicherti & - & 1 & 1 & 1 & 1 & 0 & 1 & 1 & 2 & 1 & 2 & 0 & 1 & 1 & 1 & 1 & 1 & 0 & - & 1 & 0 & 0 & 0 & 1 & 0 & 0 & 0 & 2 & 0 & 0 & $?$ & $?$ & $?$ & $?$ & $?$ & $?$ & ? \\
\hline H.macrocephalus & - & 1 & 1 & 0 & 1 & 0 & 1 & 1 & 0 & 0 & 2 & 0 & 1 & 1 & 1 & 1 & 0 & 2 & 1 & 1 & 1 & 0 & 1 & 0 & 0 & 0 & 1 & 1 & 1 & 0 & 0 & 1 & 1 & 0 & 2 & 2 & 0 \\
\hline 'H.' neogracilis & - & 1 & 1 & 1 & 1 & 0 & 1 & 1 & 1 & 1 & 2 & 0 & 1 & 1 & 1 & 0 & 1 & 1 & - & 1 & 0 & 0 & 0 & 1 & 0 & 0 & 1 & 2 & 0 & 0 & $?$ & $?$ & ? & ? & $?$ & ? & ? \\
\hline H. whidbournei & - & 1 & 1 & 0 & 1 & 0 & 1 & 1 & 0 & 0 & 2 & 0 & 1 & 1 & 1 & 1 & 0 & 2 & 1 & 1 & 1 & 0 & 1 & 0 & 0 & 0 & 1 & 1 & 1 & 0 & $?$ & $?$ & ? & $?$ & $?$ & $?$ & ? \\
\hline H. grimmi & - & 0 & 1 & - & 1 & 1 & 1 & 1 & 1 & 1 & 1 & 1 & 1 & 0 & 0 & - & - & - & - & - & - & - & - & $?$ & 1 & - & - & - & - & - & 1 & 1 & 1 & ? & $?$ & ? & ? \\
\hline H. perradiatus & - & 1 & 1 & 1 & 1 & 0 & 1 & 1 & 0 & 0 & 2 & 0 & 1 & 0 & 1 & 1 & 0 & 2 & 1 & 1 & 1 & 0 & 0 & $?$ & 0 & 0 & 1 & 1 & 1 & 0 & 0 & 1 & 1 & 0 & 2 & 2 & 0 \\
\hline H. radians & - & 1 & 1 & 1 & 1 & 0 & 1 & 1 & 0 & 0 & 2 & 0 & 1 & 1 & ? & ? & ? & ? & ? & ? & ? & ? & ? & ? & 0 & 0 & 1 & 2 & 0 & 0 & 0 & 0 & 1 & 0 & ? & 2 & 0 \\
\hline H. vargum & 0 & 0 & 0 & - & 1 & 0 & 1 & 1 & 0 & 0 & 2 & 0 & 1 & 0 & 0 & - & - & - & - & - & - & - & - & 0 & 0 & 1 & 1 & 0 & - & 1 & $?$ & $?$ & ? & 0 & 0 & 1 & 0 \\
\hline H.balclatchiensis & - & 1 & 1 & 1 & 1 & 0 & 1 & 1 & 2 & 1 & 2 & 0 & 1 & 0 & 1 & 1 & 0 & 2 & 1 & 1 & 1 & 1 & 1 & $?$ & 0 & 0 & 1 & 2 & 0 & 0 & 0 & 0 & 1 & 0 & $?$ & 2 & 0 \\
\hline H. wegelini & - & 1 & 1 & 1 & 1 & 0 & 1 & 1 & 2 & 1 & 2 & 0 & 0 & 0 & 1 & 1 & 0 & 2 & 1 & 1 & 0 & 1 & 0 & $?$ & 0 & 0 & 1 & 2 & 0 & 0 & $?$ & $?$ & $?$ & ? & $?$ & $?$ & ? \\
\hline K. dorbignyana & - & 1 & 1 & 1 & 1 & 0 & 1 & 0 & - & - & 2 & 0 & 0 & 1 & 1 & 1 & 1 & 0 & - & 1 & 1 & 0 & 0 & $?$ & 0 & 0 & 1 & 2 & 0 & 0 & $?$ & ? & ? & $?$ & ? & ? & ? \\
\hline L. montagnei & - & 1 & 1 & 1 & 1 & 0 & 1 & 0 & - & - & 2 & 0 & 1 & 1 & 1 & 1 & 1 & 0 & - & 0 & 1 & 0 & 0 & 0 & 0 & 0 & 1 & 2 & 0 & 1 & $?$ & ? & ? & ? & $?$ & ? & ? \\
\hline L. venulosus & - & 1 & 1 & 1 & 1 & 0 & 1 & 0 & - & - & 2 & 0 & 1 & 1 & 1 & 1 & 1 & 0 & - & 0 & 1 & 0 & 0 & 0 & 0 & 0 & 1 & 2 & 0 & 1 & $?$ & ? & ? & ? & $?$ & ? & ? \\
\hline L. depressa & - & 0 & 1 & - & 1 & 1 & 1 & 1 & 0 & 1 & 1 & 1 & 1 & 0 & 0 & - & - & - & - & - & - & - & - & $?$ & 1 & - & - & - & - & - & $?$ & $?$ & $?$ & 0 & 0 & 2 & 1 \\
\hline L. zenkeri & 0 & 0 & 1 & - & 1 & 1 & 1 & 1 & 0 & 1 & 1 & 1 & 1 & 0 & 0 & - & - & - & - & - & - & - & - & $?$ & 1 & - & - & - & - & - & $?$ & $?$ & $?$ & ? & 0 & 2 & 1 \\
\hline N. milleri & 0 & 0 & 1 & - & 1 & 0 & 1 & 1 & 0 & 0 & 2 & 0 & 1 & 0 & 0 & - & - & - & - & - & - & - & - & 0 & 0 & 1 & 1 & 0 & - & 1 & $?$ & $?$ & 1 & 0 & 0 & 1 & 0 \\
\hline S. consuetus & - & 1 & 1 & 1 & 1 & 0 & 1 & 1 & 2 & 1 & 2 & 0 & 1 & 0 & 1 & 1 & 1 & 0 & - & 0 & $?$ & 0 & 0 & 0 & 0 & 0 & 1 & 2 & 0 & 1 & $?$ & $?$ & $?$ & $?$ & $?$ & $?$ & ? \\
\hline S. domina & - & 1 & 1 & 1 & 1 & 0 & 1 & 1 & 2 & 1 & 2 & 0 & 1 & 1 & 1 & 1 & 1 & 2 & 0 & 1 & 0 & 0 & 0 & 0 & 0 & 0 & 1 & 2 & 0 & 1 & $?$ & $?$ & $?$ & ? & $?$ & ? & ? \\
\hline S. latior & - & 1 & 1 & 1 & 1 & 0 & 1 & 1 & 2 & 1 & 2 & 0 & 1 & 0 & 1 & 1 & 1 & 0 & - & 0 & 1 & 0 & 0 & 0 & 0 & 0 & 1 & 0 & 0 & 1 & $?$ & ? & ? & ? & $?$ & ? & ? \\
\hline S. spasskii & - & 1 & 1 & 1 & 1 & 0 & 1 & 1 & 2 & 1 & 2 & 0 & 0 & 0 & 1 & 1 & 1 & 1 & - & 1 & 0 & 0 & 0 & 0 & 0 & 0 & 1 & 2 & 0 & 1 & $?$ & $?$ & $?$ & ? & $?$ & ? & ? \\
\hline S. tatouyangensis & - & 1 & 1 & 1 & 1 & 0 & 1 & 1 & 2 & 1 & 2 & 0 & $?$ & 0 & 1 & 1 & 0 & 2 & 0 & 1 & 0 & 0 & 0 & 0 & 0 & 0 & ? & 1 & $?$ & $?$ & $?$ & ? & ? & $?$ & $?$ & $?$ & ? \\
\hline C. minor & 0 & 0 & 1 & - & 0 & 0 & 1 & 1 & 0 & 0 & 0 & 0 & 1 & 0 & 0 & - & - & - & - & - & - & - & - & 0 & 0 & 1 & 1 & 0 & - & 1 & 1 & 0 & 0 & 1 & 0 & 0 & 0 \\
\hline C. kindlei & 1 & 0 & 0 & - & 0 & 0 & 0 & 1 & 0 & 0 & 0 & 0 & 1 & 0 & 0 & - & - & - & - & - & - & - & - & 0 & $?$ & ? & $?$ & $?$ & ? & $?$ & $?$ & $?$ & $?$ & 0 & 0 & 2 & 0 \\
\hline C. iowensis & 1 & 0 & 0 & - & 0 & 0 & 0 & 1 & 0 & 0 & 0 & 0 & 1 & 0 & 0 & - & - & - & - & - & - & - & - & 0 & $?$ & $?$ & $?$ & $?$ & $?$ & $?$ & $?$ & $?$ & $?$ & 0 & 0 & 2 & 0 \\
\hline M. whiteleyi & 0 & 0 & 0 & - & 0 & 0 & 0 & 1 & 0 & 0 & 0 & 0 & 1 & 0 & 0 & - & - & - & - & - & - & - & - & 0 & 0 & 1 & 1 & 0 & - & 1 & 0 & 0 & 1 & 1 & 0 & 0 & 0 \\
\hline P. striata & 1 & 0 & 1 & - & 0 & 0 & 1 & 1 & 0 & 0 & 0 & 0 & 1 & 0 & 0 & - & - & - & - & - & - & - & - & 0 & 0 & 1 & 1 & 1 & - & 1 & 0 & 0 & 1 & 0 & 0 & 0 & 0 \\
\hline T. coria & 1 & 0 & 0 & - & 0 & 0 & 0 & 1 & 0 & 0 & 0 & 0 & 1 & 0 & 0 & - & - & - & - & - & - & - & - & 0 & 0 & 1 & 1 & 0 & - & 1 & $?$ & $?$ & ? & 0 & 0 & 2 & 0 \\
\hline
\end{tabular}

